Georgia State University

ScholarWorks @ Georgia State University

Winter 12-8-2010

\title{
Examining the Role of Communication on Sibling Relationship Quality and Interaction for Sibling Pairs With and Without a Developmental Disability
}

Ashlyn L. Smith

Georgia State University

Follow this and additional works at: https://scholarworks.gsu.edu/psych_diss

Part of the Psychology Commons

Recommended Citation

Smith, Ashlyn L., "Examining the Role of Communication on Sibling Relationship Quality and Interaction for Sibling Pairs With and Without a Developmental Disability." Dissertation, Georgia State University, 2010.

doi: https://doi.org/10.57709/1718284

This Dissertation is brought to you for free and open access by the Department of Psychology at ScholarWorks @ Georgia State University. It has been accepted for inclusion in Psychology Dissertations by an authorized administrator of ScholarWorks @ Georgia State University. For more information, please contact scholarworks@gsu.edu. 


\title{
EXAMINING THE ROLE OF COMMUNICATION ON SIBLING RELATIONSHIP QUALITY AND INTERACTION FOR SIBLING PAIRS WITH AND WITHOUT A DEVELOPMENTAL DISABILITY
}

by

ASHLYN L. SMITH

Under the Direction of Mary Ann Romski

\begin{abstract}
Sibling relationships in families of children with disabilities are generally positive despite difficulties that may result from the child's disability. Many developmental disabilities have associated communication impairments that could affect how siblings interact with each other and the closeness between them. Research has rarely addressed the role of communication skills and how potential deficits in communication may impact the sibling relationship. The purpose of this study is to examine the characteristics of sibling communication interaction patterns when one sibling has a developmental disability and the unique role that communication skills play in the quality of the sibling relationship using both self-report and observational measures. Participants were 30 mixed and same-sex sibling dyads that included one typically developing sibling and their brother or sister with an identified developmental disability. Using parent report, children with disabilities were placed into three communication status groups according
\end{abstract}


to their communication skills: emerging communicators, context-dependent communicators and independent communicators. Results indicated that when children with disabilities were independent communicators, they exhibited interactions with their siblings that were similar in terms of lexical complexity but that regardless of communication status, typically developing siblings dominated the interaction. All three communication groups differed significantly on measures of relative status/power with siblings of children who were independent communicators reporting highest levels of relative status/power. Additionally, receptive vocabulary was a significant predictor of relative status/power and proportion of intelligible utterances was a significant predictor of rivalry. Finally, although typical siblings acknowledged that their relationship would be different if their sibling with a disability had different communication skills, it did not lessen the importance of that sibling in their life. As a whole, these results represent a first step in understanding the unique role of communication skills in the sibling relationship for families of children with disabilities. It established that when children are grouped together according to their communication abilities, findings regarding relative status/power are different than what would be expected based on literature. Communication and language skills are important variables to add to the literature to further elucidate the sibling experience in families of children with disabilities.

INDEX WORDS: Sibling relationships, Developmental disabilities, Communication skills, Observation 
EXAMINING THE ROLE OF COMMUNICATION ON SIBLING RELATIONSHIP QUALITY AND INTERACTION FOR SIBLING PAIRS WITH AND WITHOUT A DEVELOPMENTAL DISABILITY

by

ASHLYN L. SMITH

A Dissertation Submitted in Partial Fulfillment of the Requirements for the Degree of Doctor of Philosophy

in the College of Arts and Sciences

Georgia State University

2010 
Copyright by Ashlyn L. Smith 2010 
EXAMINING THE ROLE OF COMMUNICATION ON SIBLING RELATIONSHIP QUALITY AND INTERACTION FOR SIBLING PAIRS WITH AND WITHOUT A DEVELOPMENTAL DISABILITY

by

ASHLYN L. SMITH

Committee Chair: $\quad$ MaryAnn Romski

Committee: Rose A. Sevcik

Christopher C. Henrich

Frank Floyd

Electronic Version Approved:

Office of Graduate Studies

College of Arts and Sciences

Georgia State University

December 2010 


\section{DEDICATION}

I would like to dedicate this document to my family. Each and every one of you has impacted my life in different and important ways. Without your influences, I certainly would not be in the position I am in today. Thank you to you all! 


\section{ACKNOWLEDGMENTS}

I would like to thank Mike Barker for his help with statistical analyses and formatting of this dissertation. I would also like to thank MaryAnn Romski and Rose Sevcik for all of their help and support both before and during my graduate school career. They have both been amazing mentors and I appreciate their guidance and would not be where I am today without them. 


\section{TABLE OF CONTENTS}

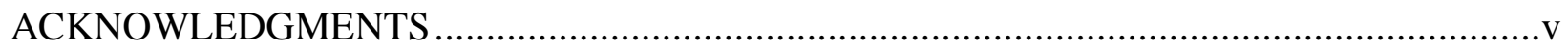

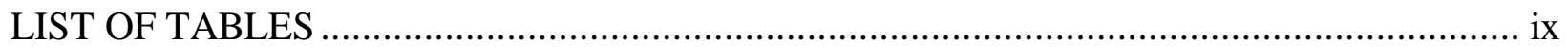

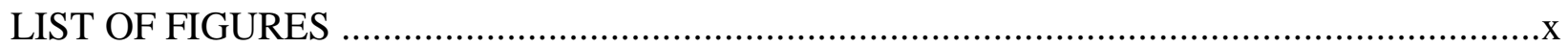

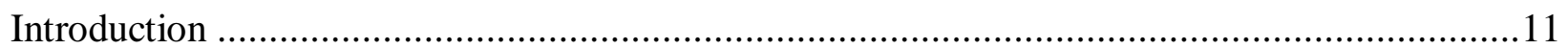

Conceptual framework for studying sibling relationships ...................................... 12

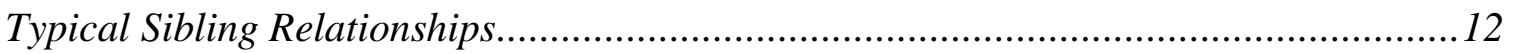

Sibling Relationships for Children with Disabilities.............................................13

Sibling relationships for typically developing children......................................... 13

Sibling relationships for children with developmental disabilities.................................. 18

Sibling Relationship and Communication Ability ....................................................26

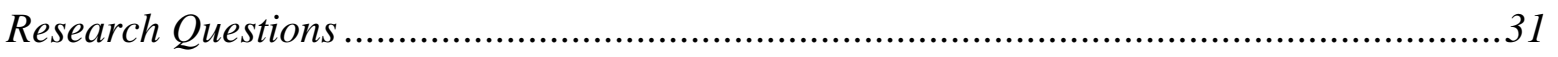

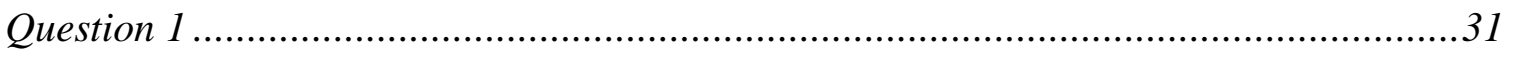

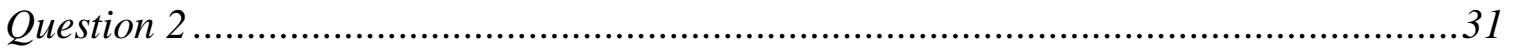

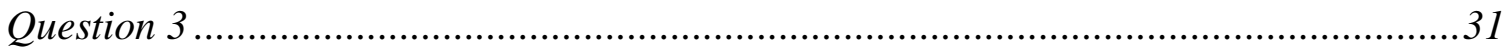

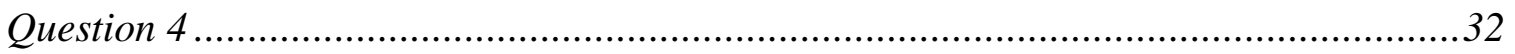

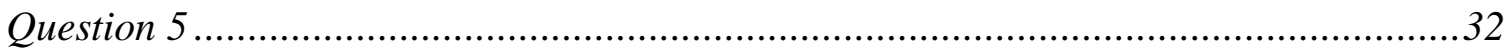

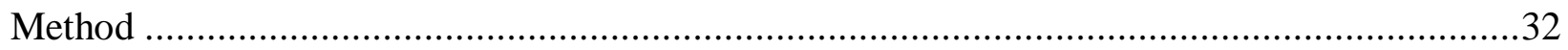

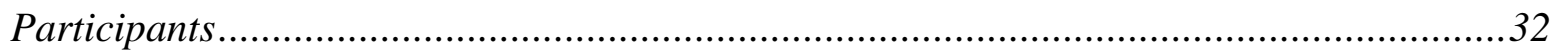

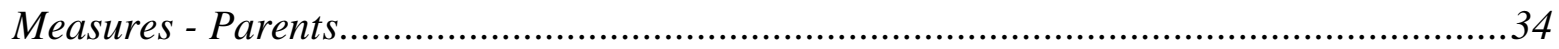


Measures - Typically Developing Siblings.

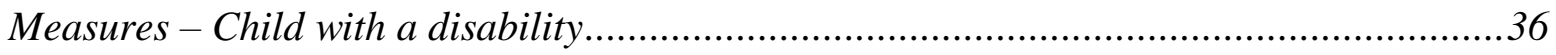

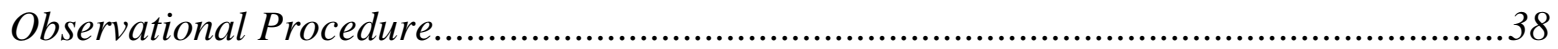

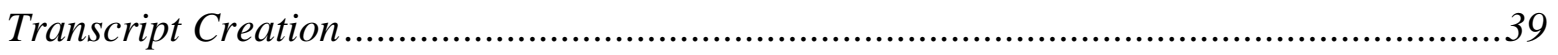

Coding Affective Quality...................................................................................4 4

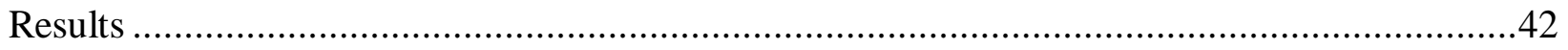

Communication status group formation.........................................................42

Communication Status Group Comparisons .............................................................44

Characteristics of Communication Interaction Patterns: ...........................................49

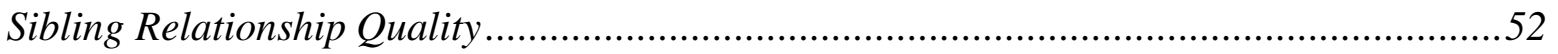

Prediction of Sibling Relationship Quality by Vocabulary and Interaction Measures: .......54

Relation of Observed Affective Quality to Self-Reported Sibling Relationship Quality .......57

Typically Developing Siblings Perceptions of Their Sibling's Communication Skills .........57

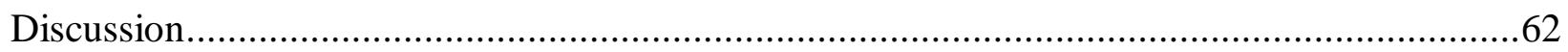

Characteristics of Communication Interaction Patterns..........................................62

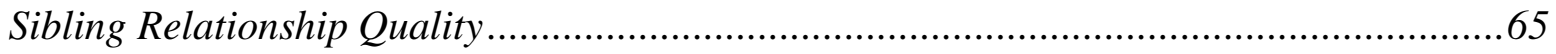

Prediction of Sibling Relationship Quality by Vocabulary and Interaction Measures.........67

Relation of Observed Affective Quality to Self-reported Sibling Relationship Quality .......69

Typically Developing Siblings Perceptions of Their Sibling's Communication Skills ........70

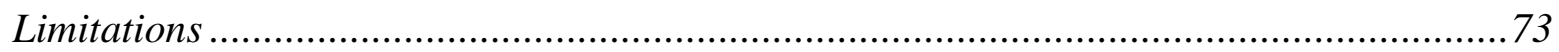




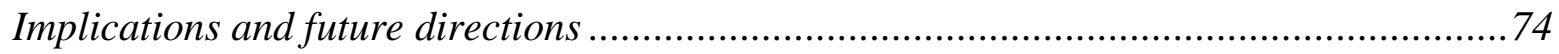

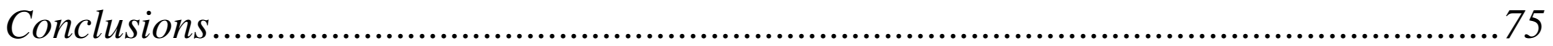

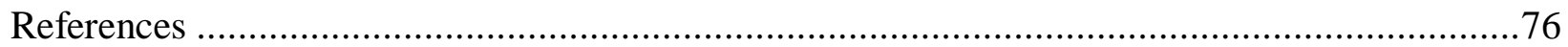

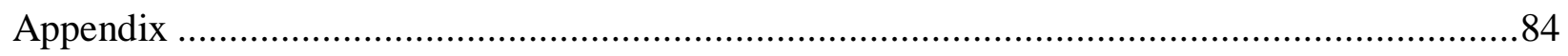




\section{LIST OF TABLES}

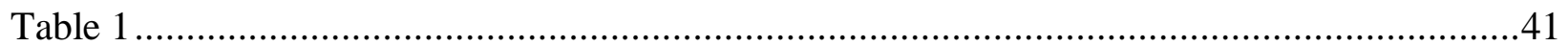

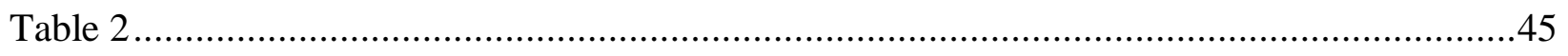

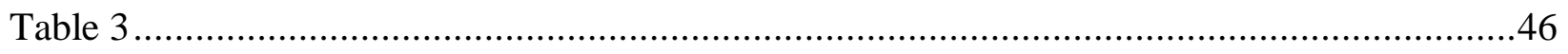

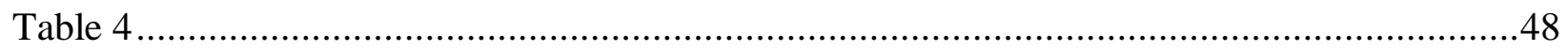

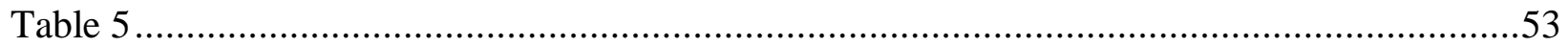

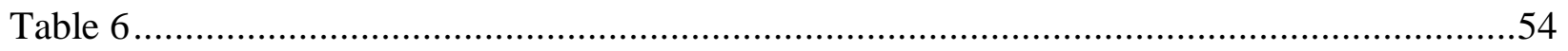

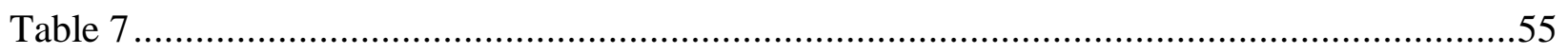

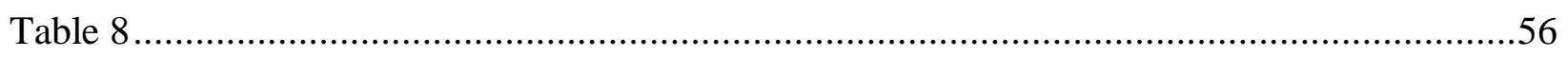

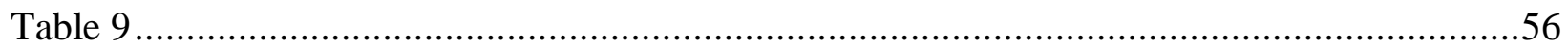

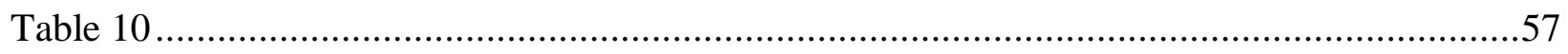

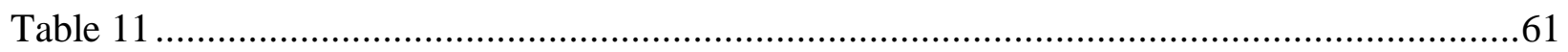




\section{LIST OF FIGURES}

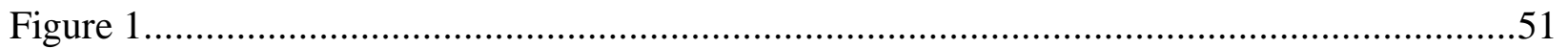




\section{Introduction}

The sibling relationship is often the most long-lasting and influential relationship of a person's life. It is unlike any other relationship in a person's life because it provides physical and emotional contact at critical life stages and often outlasts relationships with both parents and peers (Gallagher, Powell, \& Rhodes, 2006). Siblings can serve as important socialization agents for each other by providing a context for social development. This socialization process between siblings can lay the foundation for the development of sensitivity, social understanding, caregiving, and conflict management (Anderson, Hetherington, Reiss, \& Howe, 1994). Siblings can also serve as a unique source of support by acting as confidants and counselors who can provide advice to each other during difficult times (J. Dunn, 1996; Gallagher et al., 2006).

When a child in the family has a developmental disability, the typical sibling often plays a special role in the family system. In today's society this role is especially salient because most children with disabilities live at home with their parents and siblings and not in a residential setting. Early research in the area of sibling relationships for individuals with disabilities was guided by the assumption that having a sibling with a disability would lead to negative mental health outcomes for the typically developing sibling and have negative effects on the sibling relationship (Stoneman, 2005; Stoneman \& Brody, 1993). Studies resulting from this line of research, however, have shown that in general, typically developing children are not negatively affected by having a sibling with a disability. In fact, research shows that through their interactions, typical siblings both influence and are influenced by their brother or sister with a disability (Gallagher et al., 2006). Stoneman (2001) asserted that simply because relationships between siblings when one child has a disability may be different than those between typically developing siblings, it does not mean that these relationships are inferior or need intervention. In 
fact, these relationship differences can be adaptive and allow warm and close relationships to develop despite difficulties that may result from the child's disability.

Communication is the central way in which children express their wants and needs and is essential to the human experience. Many developmental disabilities have associated communication impairments that could affect how siblings interact with each other and the closeness between them. Although our knowledge about the experiences of siblings of children with disabilities has increased, it has rarely addressed the role of communication skills and how potential deficits in communication may impact the sibling relationship. The purpose of this study is to examine the characteristics of sibling communication interaction patterns when one sibling has a developmental disability and the unique role that communication skills play in the quality of the sibling relationship.

\section{Conceptual framework for studying sibling relationships}

Typical Sibling Relationships. Research on sibling relationships does not have a guiding theory of its own. In this sense, research in this area is generally regarded as "theory-free" and has largely developed under the umbrella of the larger family system (Stoneman, 2005). A family systems perspective posits that each family can be conceptualized as a system comprised of various subsystems that interact with each other in reciprocal ways (Minuchin, 1988). These subsystems include the spousal, parent-child, and sibling subsystem. In this way, family members are interconnected with one another such that when events impact one member of the family, all family members are impacted in some way (Stoneman \& Brody, 1984). In typical sibling relationships, interaction among these various family subsystems has been shown to impact the quality of the sibling relationship (Brody, Stoneman, \& MacKinnon, 1996). A parallel theory to family systems that has guided sibling research for individuals with and 
without ID has been social ecology theory. This theory emphasizes that development must always occur in context. Specifically, development is thought of as the progressive, mutual accommodation of individuals and the changing environments in which they live (Bronfenbrenner, 1977, 1986).

Sibling Relationships for Children with Disabilities. Both family systems theory and social ecology theory emphasize the importance of not looking at an individual in isolation; that every person influences and is influenced by both family members and the larger society. These two theories about family relationships have been adapted to a framework that includes individuals with disabilities. The fundamental concept of these family theories is that families are comprised of various subsystems that are interrelated. This framework takes on an added dimension when a member of the family has a disability. The typical stressors and challenges that all families face such as the birth of a new child, entrance into school, and changes in the composition of the household, are made even more acute when a member of the family has a disability (Gallagher et al., 2006). This complex system of relationships is critical for understanding the development of siblings when one child has a disability such that certain child characteristics associated with the child's disability may be expected to impact the family in a particular way which in turn may impact the sibling relationship (Stoneman, 1993; Stoneman \& Brody, 1993). Using this framework, it is possible to examine the conditions under which positive sibling relationships can develop (Dykens, 2005).

Sibling relationships for typically developing children

Like any meaningful relationship in a person's life, the sibling relationship changes across development. Siblings may play different roles in each other's life depending on the developmental period. There is a large, well developed body of literature examining the 
developmental course of typical sibling relationships. As siblings get older and move from childhood to adolescence, their relationships change in ways that are distinct from the developmental course of peer and parent-child relationships. Specifically, sibling relationships show remarkable stability in both positive and negative aspects of the relationship from childhood to adolescence with negative changes generally attributed to new friendships formed outside of the family (J. Dunn, 1992; J. Dunn, Slomkowski, \& Beardsall, 1994).

One of the main instruments used to measure sibling relationship quality has been the Sibling Relationship Questionnaire (SRQ; Furman \& Buhrmester, 1985). The SRQ was created to assess perception of sibling relationship quality in typical sibling dyads. Using an open-ended interview, the authors asked a sample of children in the fifth and sixth grade about their relationships with their brother or sister. From these interviews, categories were developed as the basis for the scales of the SRQ. This questionnaire was then given to a larger sample of fifth and sixth grade children. A factor analysis conducted to identify underlying dimensions of sibling relationship quality yielded four distinct factors: Warmth and Closeness, Relative Status/Power, Conflict, and Rivalry. Warmth/Closeness in the sibling relationship is characterized by qualities such as intimacy, prosocial behavior, companionship, nurturance, and admiration. Relative Power/Status is conceptualized as the level of symmetry in the sibling relationship characterized by nurturance of sibling, nurturance by sibling, dominance of sibling, and dominance by sibling. Conflict/Rivalry is characterized by qualities such as quarreling, antagonism, competition, and struggles over dominance. This instrument has found widespread use in assessing the quality of the sibling relationship. Generally speaking, the literature has demonstrated that the sibling relationship goes through periods of intense activity as well as 
periods of inactivity (Bank \& Kahn, 1997). This cycle of activity in the sibling relationship leads to age-related differences in levels of warmth and closeness, conflict/rivalry, and role symmetry. Buhrmester and Furman (1990) examined developmental trends in the quality of sibling relationships. Using the SRQ, the authors assessed children's perceptions of sibling relationships in a sample of third, sixth, ninth, and twelfth graders. They found that warmth and closeness tended to be highest in childhood with decreases occurring during adolescence. The reason for this decrease was due to the large amount of time that siblings spend together as children. During the school years, siblings used the social skills they learned from each other to interact with peers and other people outside of the family constellation. As children moved into adolescence, a transition occurred where siblings spent less time with each other and more time devoted to peer relationships that occurred outside of the family. This change affected the closeness of the sibling relationship by decreasing the access of siblings to each other for interaction (Cicirelli, 1995). During adolescence siblings are more likely to turn to peers for sources of support which in turn led to decreases in intimacy in the sibling relationship (Brody, Stoneman, \& McCoy, 1994; Buhrmester \& Furman, 1990). Although levels of warmth and closeness are lower during adolescence than in childhood, it is important to note that they remain relatively high. Even though siblings spend less time together during adolescence the strong emotional attachment remains (Buhrmester \& Furman, 1990).

A similar trend in the sibling relationship emerges for conflict and rivalry. Research has shown that sibling relationships are characterized by relatively high levels of conflict that are highest during childhood and early adolescence and rapidly decline during middle and late adolescence (Buhrmester, 1992). Similar to the changes in levels of warmth and closeness, this decline seems to be related to the amount of time that siblings spend together in childhood. As 
young children, they interact with each other frequently, and share similar experiences

(Gallagher et al., 2006). The more time that siblings spend together the more an opportunity exists for conflict to occur. As siblings move into adolescence, there is a marked decrease in the amount of time that siblings spend together which would be expected to decrease these negative interactions (Buhrmester \& Furman, 1990; Furman \& Buhrmester, 1985). Overall it seems that conflict and support are important to give children a variety of experiences in learning to deal with others. A healthy amount of conflict can provide an opportunity for siblings to vent their emotions, express their feelings, and engage in open communication (Brody, 1998).

Regarding role structure, there is a difference in power in the sibling relationship that is related to the developmental status of each sibling. Again, the greatest difference in role structure is present during childhood and tends to disappear during adolescence. Sibling relationships are assymetrical during childhood with the older sibling assuming a dominant role by teaching or helping the younger sibling (Buhrmester \& Furman, 1990; Stoneman, 2001). As siblings age, the role relationships become increasingly symmetrical and egalitarian in nature (Cicirelli, 1995; Stoneman, 2001). This transformation in the role structure of sibling relationships parallels other changes that occur during development. With increasing age, children typically exhibit greater self-sufficiency and are no longer in need of continuous supervision. Generally speaking, as siblings grow more confident and their developmental statuses become similar, relationships become more symmetrical and less intense although the strong emotional attachment remains (Buhrmester \& Furman, 1990).

There are several variables that refer to the status of one child relative to another child in terms of certain biologically linked characteristics that are thought to influence the quality of the sibling relationship. These characteristics are referred to in the sibling literature as "constellation 
variables" and include gender, birth order and age-spacing (Buhrmester, 1992). For gender, the most consistent finding is that females report higher levels of warmth and closeness in the sibling relationship than males. Specifically, Furman and Buhrmester (Furman \& Buhrmester, 1985) found that in same-sex dyads females reported the highest levels of warmth and closeness. In a later study, Buhrmester and Furman (1990) found that although gender did not differ between overall levels of warmth and closeness, females scored higher than males on individual scales of intimacy, companionship, similarity, and admiration. Gender does seem to be related to levels of conflict, rivalry, or relative status (Buhrmester \& Furman, 1990; Furman \& Buhrmester, 1985).

Birth order exerts its main influence on relative status within the sibling relationship. Specifically, older siblings reported greater nurturance of and dominance over younger siblings. Additionally, when siblings were the younger members of the dyad, they reported greater admiration of their older sibling than when they were the older members of the dyad (Buhrmester \& Furman, 1990; Furman \& Buhrmester, 1985; Vandell, Minnett, \& Santrock, 1987). Birth order does not affect levels of warmth and closeness within the sibling relationship but does influence levels of conflict and rivalry. This effect seems to be moderated by parental differential treatment rather than being a direct effect. Specifically, children perceived their relationships with younger siblings to be more conflicted and also reported that younger siblings were favored more by parents than older siblings (Buhrmester \& Furman, 1990; Furman \& Buhrmester, 1985; Kowal \& Kramer, 1997).

Finally, age-spacing among sibling dyads seems to show the most consistent effects across dimensions of warmth and closeness, relative status, as well as conflict and rivalry. For warmth and closeness, children reported greater affection, prosocial behavior, and admiration but less intimacy in wider spaced (four or more years) than narrow spaced dyads (Buhrmester \& 
Furman, 1990). For relative status, in wider spaced dyads, older siblings reported the greatest amount of nurturance and caretaking as well as greater admiration by the younger siblings. Conversely, greater levels of dominance were reported in the narrow spaced dyads (Buhrmester \& Furman, 1990; Furman \& Buhrmester, 1985). For overall conflict, levels of quarreling, antagonism, and competition were greater for siblings who are close in age than those who were not (Buhrmester \& Furman, 1990; Furman \& Buhrmester, 1985).

In summary, these constellation variables of gender, birth order, and age-spacing all exert consistent effects across studies on the quality of the sibling relationship. It is important to note, however, that the size of these effects tend to be relatively small (with the exception of birth order) and accounted for a small amount of variance in the quality of the sibling relationship (Buhrmester \& Furman, 1990; Furman \& Buhrmester, 1985). In fact, it appears that child temperament, parent behavior, and child age accounted for a greater amount of variance in the quality of the sibling relationship than family constellation variables did (Brody, 1998; Buhrmester, 1992; Stocker, Dunn, \& Plomin, 1989). Although it is clear that these family structure variables play a role in the quality of the sibling relationship, they should not be considered the sole explanatory variables.

Sibling relationships for children with developmental disabilities

In conceptualizing sibling relationships in children with disabilities, the predominant comparison has been between siblings of children with disabilities and siblings of typically developing children. Using the typical sibling relationship as the standard for comparison permits researchers to identify how sibling relationship quality for individuals with disabilities may be different than typical sibling relationships. Contrary to expectations, findings for sibling relationship quality in sibling dyads where one sibling has a developmental disability have 
generally been positive. Early work in this area tended to use heterogeneous samples of children with various types of intellectual disabilities. Children with Down syndrome, autism, cerebral palsy, and other disorders were grouped together. The assumption driving this grouping was that all families/siblings were affected by the child with a disability in similar ways (Cuskelly, 1999; Stoneman, 1998)

In the area of warmth and closeness, findings from self-report data have suggested that relationships are high in affective quality and may in fact be more positive than that between typical siblings. Begun (1989) examined the qualitative aspects of sibling relationships in a cross-sectional study of 46 sisters, aged 12-69, of individuals with moderate to profound developmental disabilities. Using self-report data on the SRQ from the typical sibling in the pair, results indicated that although the sibling relationship was characterized as less intimate, it was generally positive and less competitive than typical sibling relationships. McHale and Gamble (1989) compared reports on the SRQ from 62 typical children aged 8-14, half of whom had a sibling with an intellectual disability (ID) and half who did not. The authors reported that there were no significant differences between groups as children evaluated their relationship with their sibling as positive regardless of disability status. When differences were found, they were in the direction of sibling relationships for children with disabilities being more positive than typical comparison siblings.

Using observational methods, Stoneman, Brody, Davis, and Crapps (1987) examined naturalistic in-home interactions of children with and without ID and their older same-sex sibling. 32 sibling pairs, half of whom had a younger sibling with ID were observed in an unstructured interaction where siblings were instructed to engage in their normal routine and activities of their choice. They found that not only was there a high level of interaction between 
typical siblings and their younger sibling with ID but there was also no difference in affectivity between the two groups. The interactions between typical siblings and their younger siblings with ID were neither more conflicted nor more positive than the relationship between typical sibling dyads. Brody, Stoneman, Davis, and Crapps (1991) next examined interactions between 32 children with and without ID and their younger same-sex sibling in a naturalistic but more structured interaction of toy, play, and snack activities. Similar to the earlier study, the authors found no differences in affectivity between sibling groups regardless of disability status.

The studies detailed so far used heterogeneous groups of children with disabilities. There is also existing literature that examines sibling relationship quality using more homogeneous groupings of children with disabilities. The reason for using more homogeneous groupings is that certain etiologies may have specific characteristics that could affect the sibling relationship differently (Gallagher et al., 2006). In general, these studies have revealed minor differences in sibling relationship quality as a result of etiology. McHale, Sloan, and Simeonsson (1986) used an open-ended interview format to gather data for 90 typical children, age 6-15, who were siblings of 30 children with autism, 30 children with ID, and 30 typical siblings. Results indicated that on average, children's relationships with their siblings looked similar and were overall positive regardless of disability status. Among the group of children who had siblings with ID, however, there was great variability as some children described very positive and some children described very negative relationships with their siblings with ID. The relationships for typical sibling dyads were much less variable and tended to cluster around the mean. Positive relationships existed when children perceived that their parents reacted positively to the child with the disability and when they had a better understanding of the child's condition. A negative relationship predominated when the children had great concerns about the child's future, 
perceived parental favoritism toward the child with the disability, and when they experienced feelings of rejection towards the child. Although there was greater variability in relationships for siblings with disabilities, the authors concluded that the overall lack of group differences between the typical children and those with disabilities indicated that having a sibling with a disability did not necessarily result in a negative sibling relationship. Roeyers and Mycke (1995) examined sibling relationship quality using self-report data from 60 typical children who were siblings of 20 children with autism, 20 children with ID, and 20 typical children. The authors found significant differences between groups. Specifically, siblings of children with autism reported more embarrassment about their sibling than the other siblings. Although there were no significant differences between the three groups on overall quality of the sibling relationship, there was a trend for siblings of children with both autism and ID to rate their behavior towards their sibling as more positive and were more accepting than typical sibling dyads. In general, all children in the study had a positive view of their sibling relationship regardless of disability status.

More recent research has supported these earlier findings. Kaminsky and Dewey (2001) used self-report data from the SRQ to examine the quality of the sibling relationships in families of 30 children with autism, 30 children with Down syndrome (DS), and 30 typically developing children. They found that differences emerged between groups of siblings with autism and Down syndrome. Specifically, siblings of children with DS were more nurturant of their sibling and had higher levels of overall closeness than the other two groups. Siblings of children with autism reported less intimacy with their sibling and exhibited less prosocial behavior in their relationship than siblings of children with DS. Overall however, their findings supported earlier research showing positive sibling relationships for children with ID. Siblings of children with 
both autism and DS reported greater admiration of their sibling and less competition and conflict as compared to typical sibling dyads. Cuskelly and Gunn (2003) examined sibling relationships of children with Down syndrome. In a sample of 54 typical siblings of children with Down syndrome, findings from self-report data indicated that having a sibling with a disability did not damage the sibling relationship. Results indicated that siblings of children with DS did not differ significantly from comparison children and that any group differences were actually in the direction of the DS relationships being more positive than those for typically developing children.

Studies using observational methodologies have supported the self-report data. Abramovitch, Stanhope, Pepler, and Corter (1987) observed interactions between 31 typically developing children and their siblings with DS. The authors examined initiations and responses to initiations of prosocial and agonistic behaviors in the children with DS. They found that the overall nature of the sibling interaction was not altered by the presence of a child with DS and that the interactions were more positive than the interactions of typical sibling dyads. Knott, Lewis, and Williams (1995) observed interactions between 15 siblings of children with autism and Down syndrome, respectively. Like Abramovitch et al. (1987), they found no significant differences between groups in either the frequency or quality of the interactions and concluded that typical children's play was not negatively affected by having a sibling with a disability. Sibling dyads including children with autism did however show signs of impairment in that their interactions were characterized by lower rates of initiations and responses than the interactions for children with DS.

One of the main differences between sibling relationships involving individuals with ID and typical sibling relationships concerns the nature of role relationships. Unlike typical sibling 
dyads that become more egalitarian as sibling age increases, sibling relationships involving a child with ID indicate that these relationships tend to remain assymetrical regardless of whether the typical sibling is older or younger. For older siblings of children with ID, sibling relationships remain assymetrical as older siblings frequently help, teach, and manage their younger siblings with ID (Abramovitch et al., 1987; Stoneman, 2001; Stoneman, Brody, Davis, \& Crapps, 1989). For younger siblings of children with ID, Farber (1960) posited that they would exhibit what he called "role crossover" whereby younger nondisabled siblings would "catch up" developmentally to their older sibling with ID and advance ahead of their sibling, assuming role dominance. Research supports this notion demonstrating that younger typically developing children who have a sibling with ID tend to engage in roles that are not typical for other children their age. Younger, typically developing children tend to lead the interaction with their older sibling with ID and take on dominant roles involving helping, teaching, and behavior management more often than their same-aged peers in the comparison group (Abramovitch et al., 1987; Brody et al., 1991). This difference in power and relative status continues into adolescence. Eisenburg, Baker, and Blacher (1998) used questionnaire data from the SRQ and interview data to examine sibling relationships among 25 typical siblings of children and adolescents of ID with a mean age of 14 who lived at home, 20 siblings of individuals with ID who lived out of the home, and 28 control siblings of typically developing children. Control siblings reported having equal power within relationship while siblings of children with ID perceived themselves as having higher levels of relative status and power in the relationship.

Further evidence for the assymetrical nature of sibling relationships for children with ID comes from the greater amount of time spent of caregiving activities by typical siblings in than siblings of children without ID (McHale \& Gamble, 1989). Stoneman, Brody, Davis, Crapps, \& 
Malone (1991) examined ascribed roles given to siblings of children with ID by parents such as babysitting, monitoring, and assisting with day-to-day physical care. Thirty-two sibling pairs, half of whom had an older sibling with ID were observed playing with a standard toy set, sharing a snack, and watching TV. Younger siblings of children with ID assumed ascribed childcare roles such as physical care and babysitting that were typically reserved for the oldest children in family. This role is atypical of sibling relationships in the general population. Hannah and Midlarsky (2005) examined the helping behaviors by 50 siblings of children with ID in contrast with 50 siblings of typical children. They found that siblings of children with ID provided more custodial care (defined as bathing, dressing, babysitting, and feeding) and emotional support to their siblings with ID than did those whose siblings did not have ID. They also found that younger siblings of children with ID provided more custodial care than younger siblings of typical comparison children. These findings are consistent with the notion that younger siblings of children with ID engage in dominant roles more often than their same-aged peers. Regardless of the asymmetries that exist in the sibling relationships of children with ID, there is not a negative effect on the quality of the sibling relationship that was anticipated by many of these researchers.

Just as with typical sibling dyads, the constellation variables of gender, birth order, and age-spacing play a role in sibling relationship quality for individuals with disabilities. For gender, the findings have been somewhat contradictory. Some studies have found that although boys engage in more caretaking behaviors than their typical male peers, females assume more helping and caregiving behaviors for their sibling with a disability than their male counterparts. Specifically, sisters of children with disabilities were more likely to participate in day to day physical care such as bathing, dressing, feeding, and babysitting, as well as teaching and 
managing behaviors than brothers (Brody et al., 1991; Hannah \& Midlarsky, 2005; Stoneman et al., 1987; Stoneman et al., 1991). Other studies have found no significant differences for gender as both boys and girls reported engaging in more caretaking activities and more involvement in daily tasks than typically developing comparison siblings (Cuskelly \& Gunn, 2003; McHale \& Gamble, 1989).

Birth order and age-spacing do not seem to have as much influence on the sibling relationship for children with disabilities mainly due to the asymmetry that exists in the sibling relationship. Younger siblings of children with disabilities assume more caretaking and helping roles than is seen for children their age in the typically developing population (Hannah \& Midlarsky, 2005; McHale \& Gamble, 1989; Stoneman et al., 1991). These roles do not, however, have an effect on the quality of the sibling relationship as measured by warmth and conflict (Begun, 1989; Cuskelly \& Gunn, 2003).

Overall, these studies suggest that the sibling relationship is not negatively affected by having a sibling with ID. Across both self-report and observational methodologies, the sibling relationship can even be characterized as more positive and less conflicted than typical sibling relationships. There are some differences, however, based on the etiology of the children with disabilities. Children in dyads that include children with autism tend to interact less frequently and their relationship is characterized as less intimate than those of both children with ID and typically developing children. This appears to be related to the social deficits in children with autism, such as difficulty understanding the perspectives of others and understanding emotion (Kaminsky \& Dewey, 2001). It is important to note that although these etiological differences may alter the context of the interaction, the quality of the relationship and interaction are not negatively affected as siblings still rate their relationships as positive (Stoneman, 2005). In fact, 
parents and siblings both report various positive effects of having a sibling with a disability such as increased sensitivity, caring, empathy, greater maturity, and sense of responsibility (Dykens, 2005; Hastings \& Taunt, 2002).

Sibling Relationship and Communication Ability

While the quality of the sibling relationship is not negatively affected by having a sibling with a developmental disability, the role that the ability (or inability) to communicate may play in the sibling relationship is unclear. Communication is an important component of any relationship. If the ability to communicate is impaired, it may impact the relationship in some way. This issue has not been addressed specifically in the current literature for siblings of children with disabilities. Studies that have investigated communication ability have done so only in the context of larger studies.

Stoneman et al. (1987) investigated naturalistic sibling interactions between older typically developing siblings and their younger siblings with ID. Within the interaction, typical siblings were able to bridge the gap in competencies and found activities that permitted the siblings to play together. Language skill of the sibling with ID was only predictive of the amount of play between siblings. Brody et al. (1991) conducted a similar study, but with a more structured activity, with younger typically developing siblings and their older siblings with ID. They found evidence that younger siblings engaged in more dominant roles involving helping, teaching, and behavior management with their older sibling with ID. Children with ID who had lower adaptive and language competencies exhibited more assymetrical relationships. Stoneman and Brody (1993) argued in a review of their work, that children with ID who had higher cognitive and linguistic skill exhibited more symmetrical relationships with their typical siblings than children with ID who had lower cognitive and linguistic skill. Having a sibling with mild to 
moderate ID seemed to alter the context of the interaction but did not affect either the frequency or quality of the sibling interaction. In general, the more severe the skill deficit of the child with disability, the larger the discrepancy between play levels and the more difficult it was to overcome.

More recent studies that have included communication as part of their studies have found that language ability may have differing impacts on the sibling relationship and adjustment. Kaminsky and Dewey (2001) compared the sibling relationship of children with Down syndrome (DS), autism, and children without other disabilities. They found that children with autism were not as verbal as the children with DS. In fact, $10 \%$ of the children with autism did not communicate through either signed or spoken language. They found that the sibling relationships of children with autism were less nurturing and less prosocial overall than the relationships of both DS and children without disabilities. The authors inferred that it was the communication deficits of these children that resulted in a lower level of negative verbal interactions between the siblings. Pilowsky, Yirmiya, Doppelt, Gross-Tsur, and Shalev (2004) examined sibling adjustment (socialization skills and behavior problems) in a sample of children who were diagnosed with autism, ID, and developmental language delay (DLD). Diagnoses of DLD were defined as IQ in the normal range and language ability at least one standard deviation below the mean on a standard language test. These children with DLD all used spoken language as their primary mode of communication. They found that overall there were no differences in sibling adjustment across the three groups. On measures of socialization skills and behavior problems, siblings were well functioning compared to normative data suggesting that most are reasonably well adjusted. There were differences, however, for siblings in the autism and ID groups whose siblings were defined as nonverbal. Specifically they found that siblings of 
children in both the autism and ID groups who were nonverbal exhibited lower socialization skills and greater behavior problems. This was not the case with siblings who had the less severe diagnosis of developmental language delay.

Other research has not looked specifically at communication but looked rather at characteristics of the interaction that may be affected by communicative skills such as initiations, responses, and imitations to prosocial and agonistic behaviors. Prosocial behaviors included, but were not limited to affection, approval, praise, and comfort while agonistic behaviors included directive commands, insults, and threats of aggression. Abramovitch, et al. (1987) found that children with DS were less active in initiating prosocial and agonistic behaviors and responded less to agonistic behaviors than their typically developing siblings. They did, however, imitate their typical siblings at a greater rate than siblings of children with autism. In a similar study, Knott, et al. (1995) examined sibling interactions and found again that children with DS initiated fewer prosocial behaviors and responded less to agonism but imitated more than typical siblings. Children with autism, however, exhibited lower rates of interaction, responded to fewer prosocial behaviors, and imitated less than children with DS. Although these studies did not specifically address communication skills, the authors speculated that the interaction deficits were related to communication difficulties and prevented them from participating fully in the interaction with their siblings. In both of these studies, however, the actual interaction between children with autism or DS was not negatively affected; typical siblings in both groups rated their interactions as positive and exhibited greater admiration for their sibling with a disability than did typically developing children (Abramovitch et al., 1987; Knott et al., 1995).

This question has been investigated in samples of children with communication disorders but not with samples of children with intellectual or developmental disabilities. Mcgillicuddy- 
De Lisi (1993) examined the effect of communicative competency on sibling interactions for children with an expressive speech disorder but intelligence in the normal range. The author found that children who were expressively delayed in communication skills behaved like younger children in typical dyads regardless of their birth order. Specifically, they were relegated to a somewhat subordinate status in the relationship as their typically developing sibling dominated the interaction. The author suggested, however, that having the opportunity to interact with their older typically developing sibling would benefit the child with the communication disorder through exposure to more mature speech models.

Barr, McLeod, and Daniel (2008) examined the role of communication abilities on the sibling relationship for six children (5-8 years old) with speech impairments and their typically developing siblings (5-14 years old). The speech impairment of these children ranged from difficulty saying a few sounds to severely unintelligible speech but all children were within normal limits on measures of cognition and hearing. The authors used semi-structured interviews that contained questions about activity and participation in society for the children. These interviews were analyzed first by identifying meaning statements and then by analyzing these meaning statements into common themes. They found that interactions between typical siblings and children with speech impairment looked generally the same as those between typically developing children and that overall there was very little disturbance to the sibling relationship. The typically developing siblings spoke about spending a lot of time with their sibling, the activities they enjoyed doing together, and the positive attributes of their sibling's personality. They also found that when the sibling relationship was moved out of the private arena, the typically developing siblings altered their roles to accommodate the needs of their sibling with a speech impairment. For example, the typically developing siblings often took on 
the roles of interpreter and protector with their siblings. They protected their siblings at times when they experienced bullying and interpreted their siblings' communication when they were around others who did not understand their attempts at communication. Barr and colleagues highlighted the fact that this type of role has not been found in the general disability literature and may be unique to those children with speech impairments. Although this study consisted of a very small sample size and included participants with speech impairment and no associated cognitive difficulties, it highlights the unique role that siblings of children with communication deficits have in a relationship.

In summary, it is evident from the current literature that communication skill plays an important role in the sibling relationship even though it has not been the main focus of studies for children with disabilities. In the two studies where the role of communication has been explored for children with communication disorders, the authors found that a similar type of role asymmetry exists within the sibling relationship that is characteristic of the relationships for children with disabilities. The typical siblings also have certain roles within their relationship that are beneficial to their sibling with a communication disorder. In the literature for children with disabilities there have been no studies to date that group children based on their communication skills. One way to classify individuals with disabilities according to their communication skills is to group them based on their distinct communication needs and the role that communication partners play. The Social Network Inventory (Blackstone \& Hunt-Berg, 2003) has been used to place individuals on a continuum starting with emerging communication (no means of symbolic expression), to context-dependent communication (reliable symbolic communication but only with specific contexts or partners), to independent communication (ability to communicate any message, to any partner, in any context). Grouping children in this 
way may serve as a starting point from which we can begin to understand the unique role that communication plays in the sibling relationship for children with disabilities.

\section{Research Questions}

The purpose of this study was to examine the quality of the sibling relationship when one sibling had an intellectual or developmental disability and the unique role that communication skills played in that relationship. Specifically, this study addressed five main research questions.

Question 1. What are the characteristics of siblings' communication interaction patterns for sibling dyads that include a child with a disability? I expected that siblings of children with disabilities would play a more dominant role in the interaction as demonstrated by higher mean length of utterance in morphemes, longer mean length of turn, and higher type token ratio than their sibling with a disability and that this would be moderated by the communication status of the children with disabilities.

Question 2. Is sibling relationship quality impacted by the communication status of the child with a disability? I expected that typically developing siblings of emerging communicators would report lower levels of warmth/closeness and conflict, and greater levels of relative status/power and rivalry as compared to both context-dependent and independent communicators.

Question 3. Do aspects of vocabulary and communication skill of the child with a disability predict dimensions of sibling relationship quality? I expected that both standard measures of vocabulary ability and transcript interaction measures would predict dimensions of sibling relationship quality such that siblings of children who perform higher on these measures would report higher levels of warmth/closeness and conflict, and lower levels of relative status/power and rivalry. 
Question 4. How does affective quality as measured in the observation correlate to selfreport measures of sibling relationship quality? I expected that observational measures of affect within the interaction would show a low correlation with the self-report measures of sibling relationship quality.

Question 5. What features characterize non-disabled siblings' perceptions of their sibling's communication skills? I expected that siblings of children who were emerging communicators would answer questions differently than siblings of children who were contextdependent or independent communicators. Specifically, siblings of emerging communicators would be more likely to indicate that communication skills had an impact on their relationship than siblings of context-dependent or independent communicators.

Method

\section{Participants}

Thirty mixed and same sex gender sibling dyads (21 same, 9 mixed) participated in this study. Participant selection criteria for the typically developing sibling included being between the ages of 10 and 18, and having a sibling with an identified developmental disability, other than delayed speech and language impairment or deafness/hearing impairment. All had speech and language skills within the typical range. Participant selection criteria for the child with a disability required that they be younger than the typical sibling and within four years of the age of the typically developing sibling, making their age range between 6 and 18. This constraint was placed on the sample because the literature shows that siblings who have large differences in age have much different experiences than those closer in age due to differences in the developmental progression of the relationship (Cuskelly, 1999; Stoneman, 2005). Ten children in this sample had a diagnosis of Down syndrome, 11 had Autism, and the remaining nine 
children had disabilities such as Cerebral Palsy, Williams syndrome, Angelman syndrome, and a developmental/intellectual disability of unknown origin.

Since the dyads recruited for this study were 18 years of age and younger, recruitment was targeted towards parents. Recruitment flyers were sent to various intervention services sites, family support networks, disability organizations, and sites that target typical siblings of children with disabilities, such as sibshops, in the southeastern United States including metro Atlanta, North Carolina, and Tennessee. Families were asked to participate in a project that would examine communication skills and sibling relationships in families of children with disabilities. They were told that participation would include one visit to their home approximately two hours in length, during which siblings would engage in a ten-minute interaction that would be videotaped, the child with a disability would participate in a brief language assessment, and both parents and the typically developing sibling would complete several questionnaires. Interested parents contacted the primary investigator about their participation and a home visit was scheduled. In cases where there were multiple typically developing siblings that fit the selection criteria, the child closest in age to the child with the disability was chosen for participation in this study.

The children with disabilities included nine females and 21 males ranging in age from 6 to 15 years with an average age of $10.71(S D=2.61)$. The typically developing siblings included 18 males and 12 females who ranged in age from 10 to 17 years with an average age of 12.70 $(S D=2.02)$. Eighty percent of the children were Caucasian and $20 \%$ were Black or AfricanAmerican. The participating parent included 28 mothers, one father, and one grandmother (who was the primary caregiver) ranging in age from 35 to 57 years with an average age of 45.79 ( $S D$ = 4.25). Twenty-five of the participating parents/primary caregivers were Caucasian and five 
were Black or African-American. One parent/primary caregiver completed high school, seven completed some college, 14 graduated college, and eight completed a graduate or professional degree. All children were in a public or private educational setting with exposure to other peers. This placement was true for all children with disabilities even in the few instances where their typically developing siblings were homeschooled.

\section{Procedure: Home Visit}

First, the participating parent completed a consent form that allowed both the typically developing child and their sibling with a disability to participate in the study. The typically developing sibling also completed an assent form indicating their desire to participate. Although the child with a disability did not complete an assent form, they were asked about their willingness to participate in the study and no child declined participation. All children agreed to participate in the study. After obtaining consent and assent, the parent completed a Demographic Information form that gathered information about family characteristics, household composition, exposure to peers and other adults and challenging behaviors for the child with a disability.

The sibling dyads then engaged in a 10-minute semi-structured videotaped activity during which they made a snack together. Upon completion of the activity, the typically developing sibling completed two forms, (the Sibling Relationship Questionnaire and the Sibling Communication Questionnaire), that asked them about their relationship with their sibling and how their perceptions about their sibling's communication skills. Simultaneously, the primary investigator completed vocabulary assessments with the child with a disability.

\section{Measures - Parents}

Prior to participation in the study, parents completed a brief measure that asked two questions pertaining to the communication skills of their child with a disability. The first 
question asked them to choose the primary way their child communicated from four options: gestures, simple words, phrases, and sentences. The second question asked if their child needed help in order to be understood by others. The choices were yes, no, and sometimes.

Parents completed the Vineland Adaptive Behavior Scales, Second Edition (Vineland-II; Sparrow, Cicchetti, \& Balla, 2005) for the sibling with a developmental disability. This measure examined adaptive behavior in four domains and was given in an interview format and was appropriate across the age span. The Communication domain measured receptive, expressive, and written language abilities. The Daily Living Skills domain examined independent living skills in the personal, domestic, and community domains. The Socialization domain measured an individual's ability to develop and maintain interpersonal relationships, coping skills, and to engage in social interaction through play and leisure time. The Motor Skills domain measured an individual's gross and fine motor abilities. Scores on these four domains combined to yield an overall measure of adaptive behavior. This measure has a long history of use for individuals with a wide range of developmental and intellectual disabilities. Internal consistency reliabilities of the domain and Adaptive Behavior Composite range from the upper .80s to low .90s.

\section{Measures - Typically Developing Siblings}

The typically developing siblings completed the Sibling Relationship QuestionnaireRevised (SRQ-R; Furman \& Buhrmester, 1985). This self-report measure includes 48 items, forming 16 scales each composed of 3 questions. The SRQ-R assessed the typical sibling's perceptions of the relationship and behaviors towards their sibling. Items are rated with a 5-point Likert scale ranging from "hardly at all" to "extremely much". Items included in the questionnaire were derived from open-ended interviews with children in the fifth and sixth grades. Children's responses were organized by categories, which were derived from the 
different relationship characteristics the children described. The main categories of relationship qualities identified by the children were grouped together to form the 16 scales. A principal component analysis identified 4 factors from the scales: Warmth/Closeness (prosocial behavior, affection, companionship, similarity, intimacy, admiration of and admiration by the sibling), Relative Status/Power (nurturance of and nurturance by the sibling, dominance of and dominancy by sibling), Conflict (antagonism, quarreling, competition), and Rivalry (parental partiality). The internal consistency of the factor scales in this sample was $0.80,0.81,0.84$, and 0.74, respectively. The SRQ-R factor scores have high test-retest reliability and have been validated for both school-aged children and adolescents (Buhrmester \& Furman, 1990; Furman \& Buhrmester, 1985). This measure also has a long history of use with siblings of children with intellectual and developmental disabilities (Begun, 1989; Eisenberg et al., 1998; Kaminsky \& Dewey, 2001; McHale \& Gamble, 1989).

The typically developing siblings also completed the Sibling Communication Questionnaire (Smith, 2010) developed specifically for this study. This questionnaire included 10 questions and used a combination of multiple choice, Likert scale and open-ended responses. The questions asked typical siblings about their perception of the communication skills of their sibling with a disability and how communication difficulties may impact their relationship. Because research to date has not addressed these questions, the open-ended responses permitted an exploration of issues related to communication that are important to the typical sibling's relationship with their brother or sister. The SCQ is included in the Appendix. Measures - Child with a disability

The Peabody Picture Vocabulary Test, Fourth Edition (PPVT-4; L. M. Dunn \& Dunn, 2007) was given to the children with disabilities as a measure of receptive vocabulary. This is a 
norm-referenced measure for both children and adults that is untimed and individually administered. Each child was shown a page that consisted of four full-color pictures and was asked to select the picture that best illustrated the meaning of the stimulus word. The child could either point to the picture or say the number of the picture. There were 19 sets of items grouped into 12 items each that were arranged in order of increasing difficulty. Testing began when the basal set was established which is the lowest item set that contained one or zero errors. Testing was stopped when the child reached the set where they made eight or more errors. Internal consistency reliability measurements averaged .97 for the sample of typically developing children on which this measure was normed. This measure has also been used extensively with children and adults with intellectual disability and the fourth edition included standardized norms on a sample of children with intellectual disability.

The Expressive Vocabulary Test, Second Edition (EVT-2; Williams, 2007) was given to children with disabilities in this study as a measure of expressive vocabulary. This measure was individually administered and norm-referenced for children and adults aged 2 years 6 months through 90 years and older. It measured expressive vocabulary knowledge with two types of items: labeling and synonym. This measure includes 190 items arranged in order of increasing difficulty. The child was presented a picture from a test easel and responded with one word that provided an acceptable label for the picture (What do you see?), answered a specific question about the picture (What is she doing?), or provided a synonym for a word that fit the pictured context (Tell me another word for mother.). Testing began when the child correctly answered five consecutive items. Testing stopped when the child incorrectly responded to five consecutive items. Internal consistency reliability measurements averaged .96 for the sample of typically developing children on which this measure was normed. As with the PPVT-4, this measure has 
also been used extensively with children and adults with intellectual disability and the second edition included standardized norms on a sample of children with intellectual disability.

In order to be consistent across every child, the PPVT was always given first followed by the EVT. For the purposes of this study, raw scores on both the PPVT-4 and EVT-2 were used in all analyses. This was due to the fact that a small percentage of children were not able to obtain a basal score on either test and thus they could not receive a standard score.

\section{Observational Procedure}

Sibling dyads participated in a 10-minute structured videotaped interaction using a standard partner protocol designed to elicit communication behaviors similar to the one used by Romski, Sevcik, Adamson and Bakeman (2005). The siblings engaged in a snack making activity that children of all ages can participate in together and is also designed to elicit communicative behaviors between the siblings. The majority of sibling dyads made a snack that involved decorating and eating cookies together. However, in six cases, the sibling dyads made other snack items that fit the children's dietary restrictions or likes and dislikes. Regardless of the type of snack made together, the format was the same. The typical sibling followed a script of ten short segments related to making a snack and included the following: a) greeting and reason for making a snack, b) invitation to join in making the snack, c) a discussion about what is going to take place, d) providing problem solving opportunities, e) provide an opportunity for the sibling with a disability to initiate conversation, f) prepare and eat the snack, g) clean up of snack, h) closing and goodbye, i) exit. Although parents generally left the room as the sibling dyads completed the activity together, some parents sometimes watched the interaction but always stayed in the background and did not become directly involved in the interaction between the siblings. 


\section{Transcript Creation}

From the videotaped interaction, language transcripts, using Systematic Analysis of Language Transcripts (SALT; Miller \& Chapman, 1985) were created to characterize the sibling dyad communications during the 10-minute videotaped observation. Transcribing was completed by the primary investigator and an undergraduate research assistant who was masked to the questions of interest. The primary investigator was previously taught to create language transcripts using SALT conventions. The undergraduate research assistant was taught by the primary investigator using a transcription manual that was adapted from that used by Romski et al. (2010). SALT defined an utterance “....as a sentence or phrase, reflecting a single thought. The primary goal is to document "thought completion". Determining what constitutes an utterance is simple when a turn consists of a single sentence. As a general rule, turns consisting of several sentences may be broken down into single sentences, each transcribed as a separate utterance. Falling/rising intonation and the presence of a pause helped determine the completion of a thought. Utterances were transcribed as unintelligible (XX is the SALT convention) when the transcriber was unable to understand the speaker's vocalization after listening to the utterance three times.

To ensure that the transcripts were a reliable representation of the interaction, the undergraduate research assistant independently viewed and transcribed the 10-minute videotaped observation. The primary investigator then reviewed the transcript while watching the videotaped interaction and made corrections and changes as appropriate according to SALT conventions and the transcription manual. Any errors or discrepancies were discussed with the undergraduate research assistant. Finally, transcripts were error checked again by the primary investigator to ensure maximum accuracy. 
From the transcripts, the SALT program automatically calculated communication interaction measures for both the typical sibling and the child with a disability. Four measures were used for the child with a disability: mean length of utterance in morphemes (MLUm), type/token ratio, mean length of turn in utterances (MLT), and proportion of intelligible utterances. Three measures were used for the typical sibling: mean length of utterance in morphemes (MLUm), mean length of turn in utterances (MLT), and type token ratio. These measures are defined in Table 1. In more general terms, MLUm is a measure of lexical complexity and children who exhibit larger MLUm have more complex morphological and syntactic skills. An individual who has a larger MLT is using more consecutive utterances during one turn than their conversational partner. Type token ratio is a measure of lexical variation in speech. This ratio was calculated by dividing the number of different words (types) by the total number of words spoken (tokens). A larger type token ratio indicates that an individual is using more different types of words during an interaction. 
Table 1

Communication Interaction Measures as Defined by SALT

Mean length of utterance in morphemes Total number of morphemes used by speaker divided by total number of speaker utterances

Type/token ratio Total number of different words spoken by child divided by total number of words spoken by the child

Mean length of turn in utterances Number of utterances used by the speaker by the number of turns taken by the speaker

Speaker turn One or more consecutive utterances by a single speaker Proportion of intelligible utterances Number of speaker intelligible utterances divided by total number of speaker utterances

\section{Coding Affective Quality}

The affective quality of the interaction was described by the presence and overall proportion of positive and negative behaviors in both the child with a disability and the typically developing sibling. These behaviors are common in the literature that examines affective quality of sibling interactions (Stoneman et al., 1987; Stoneman et al., 1991). Positive behaviors included hugs, kisses, affectionate touches, laughing, smiling at the other sibling, and praise. Negative behaviors included hitting, pushing, fighting, threatening, quarreling with/insulting other sibling, negative facial expression, name calling, and yelling. An interval coding scheme 
was used to characterize these behaviors. The primary investigator and undergraduate research assistant watched the videotapes together until the assistant was trained to a standard. Each videotape was looked at twice; once to examine affect for the child with a disability and once to examine affect for the typically developing sibling. The presence of either positive or negative behaviors for each sibling in the dyad was observed every 15 seconds during the 10 minute interaction. If an interval did not contain either positive or negative behaviors, the interval was coded as neutral. The occurrence of these affective behaviors were coded only once during each 15-second interval. According to Bakeman and Gottman (1997), an interval of 10-15 seconds is sufficient to code salient events of interest without losing important information. At the end of the 10 minute interaction, the frequency of affectively positive, negative, and neutral behaviors were calculated and the overall proportion of the interaction during which the sibling dyads exhibited these particular behaviors was determined. Twenty percent of the 30 observations $(\mathrm{n}=$ 6) were randomly selected by the primary investigator and assessed for inter-observer agreement using percent agreement. The average percentage agreement for positive, negative, and neutral behaviors was $0.86,0.97$, and 0.75 , respectively.

\section{Results}

\section{Communication status group formation.}

The communication categorizations used for this study were drawn from concepts identified by the Social Networks Inventory (Blackstone \& Hunt-Berg, 2003), which was designed to highlight the key role that communication partners play during interactions with individuals with a severe communication disorder. Specifically, it differentiates communicators based on observable expressive communication behaviors rather than on receptive language, cognitive abilities, or communication needs (Dowden, 1999; Dowden \& Cook, 2002). This 
inventory places individuals on a continuum starting with emerging communication (no means of symbolic expression), to context-dependent communication (reliable symbolic communication but only with specific contexts or partners), to independent communication (ability to communicate any message, to any partner, in any context).

For the purpose of this study, children were placed into communication groups based on parents' responses given on the measure they completed prior to participation in the study that asked two questions pertaining to the communication skills of their child with a disability. From the responses given by parents, children with disabilities were classified into the following three groups: Nine children (30\% of the sample) were classified as independent communicators. These parents reported that their children did not need help from a parent or familiar partner to be understood by others and used sentences as their primary mode of communication. Eleven children (37\% of the sample) were classified as context-dependent communicators. These parents reported that their children sometimes needed help from a parent or familiar partner to be understood by others and primarily communicated by phrases and sentences. Ten children (33\% of the sample) were classified as emerging communicators. These parents reported that their children needed help from a parent or familiar partner to be understood by others and communicated primarily through gestures, simple words, and phrases. Of these ten children, three children also used a speech-generating device (SGD) with varying degrees of use for communication.

Table 2 presents demographic characteristics for each communication status group. Differences between the independent, context-dependent, and emerging communication groups were examined on several family demographic variables using one-way Analysis of Variance (ANOVA) and chi-square tests. For all analyses, the communication status groups were 
compared with each other. One-way ANOVA's indicated no group differences on either the participating siblings' age, $F(2,27)=1.79, p>.05$ or the age of the child with a disability, $F(2$, 27) $=0.40, p>.05$. Chi-square analyses indicated that gender of the children with disabilities $\chi^{2}$ $(2, N=30)=1.63, p>.05$, and gender of the typically developing siblings $\chi^{2}(2, N=30)=3.51, p$ $>.05$ did not differ among the three groups. For education level, chi-square analyses indicated that there were no group differences for mothers $\chi^{2}(6, N=30)=4.25, p>.05$, or fathers, $\chi^{2}(4$, $N=30)=4.17, p>.05$.

\section{Communication Status Group Comparisons}

To ensure that the communication groups exhibited different profiles, children's performance on measures of adaptive behavior, vocabulary, and communication interaction most related to expressive language were compared using one-way ANOVA's. These results are shown in Table 3 and indicated that the groups differed significantly on all variables. Tukey post hoc tests indicated that the three groups differed from each other but not in predictable ways. On the PPVT, EVT, and MLUm all three communication groups differed significantly from each other. On the adaptive behavior composite of the Vineland and proportion of intelligible utterances, the context-dependent and independent groups did not differ from each other but both differed significantly from the emerging communicators. Although independent and contextdependent communicators did not differ significantly on these two measures, the fact that the other three measures (both standardized vocabulary and lexical complexity measures) differentiated all three groups validates the use of parent report for group formation in this sample and indicated that they represented distinctly different profiles. 
Table 2

Demographic Characteristics by Communication Status Group

Context-

Independent dependent Emerging

$(\mathrm{n}=9) \quad(\mathrm{n}=11) \quad(\mathrm{n}=10)$

Variable

Mean (SD) Age of Child with

Disability

$11(3)$

$10(2)$

$10(3)$

Mean (SD) Age of Typical Sibling

$14(3)$

$12(1)$

$13(2)$

Gender (\% Male)

Child with Disability

78

55

80

Typical Sibling

56

46

80

Diagnosis of Child with Disability

Down Syndrome

Autism

Cerebral Palsy

Other*

Parent Education (Frequency)
0

4

2

3
5

2

2

2

1
Some College

Graduated College

3

5

0

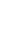

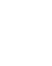

3

\footnotetext{
Note. Other diagnoses included Angleman
intellectual disability of unknown origin.
} 
Table 3

Children's performance on vocabulary and interaction measures based on communication status

\begin{tabular}{|c|c|c|c|c|c|c|c|}
\hline & $\begin{array}{l}\text { Independent } \\
(\mathrm{n}=9)\end{array}$ & $\begin{array}{c}\text { Context-dependent } \\
(\mathrm{n}=11)\end{array}$ & $\begin{array}{l}\text { Emerging } \\
(\mathrm{n}=10)\end{array}$ & & & & \\
\hline Variable & $\mathrm{M}(\mathrm{SD})$ & $\mathrm{M}(\mathrm{SD})$ & $\mathrm{M}(\mathrm{SD})$ & Range & Skew & Kurtosis & F Test \\
\hline \multicolumn{8}{|l|}{ Vineland Adaptive Behavior Scales } \\
\hline Adaptive Behavior Composite & $71(7)_{\mathrm{a}}$ & $66(11)_{\mathrm{a}}$ & $57(9)_{\mathrm{b}}$ & $47-91$ & $-0.01(0.43)$ & $-0.64(0.83)$ & 7.62 \\
\hline \multicolumn{8}{|l|}{ Vocabulary Measure } \\
\hline PPVT Raw Score & $110(23)_{\mathrm{a}}$ & $83(25)_{b}$ & $54(27)_{\mathrm{c}}$ & $21-144$ & $-0.19(0.43)$ & $-0.49(0.83)$ & 15.05 \\
\hline EVT Raw Score & $97(21)_{\mathrm{a}}$ & $73(14)_{b}$ & $42(33)_{\mathrm{c}}$ & $0-146$ & $-0.42(0.43)$ & $0.65(0.83)$ & 12.59 \\
\hline \multicolumn{8}{|l|}{ Transcript Interaction Measures } \\
\hline MLUm & $3.84(1.07)_{\mathrm{a}}$ & $2.20(0.57)_{b}$ & $1.29(0.81)_{\mathrm{c}}$ & $0.00-5.48$ & $0.92(0.43)$ & $1.20(0.83)$ & 14.72 \\
\hline MLT & $3.98(1.72)$ & $2.43(0.87)$ & $1.71(1.02)$ & $0.15-6.65$ & $1.04(0.43)$ & $1.46(0.83)$ & \\
\hline Type Token Ratio & $0.52(0.11)$ & $0.47(0.16)$ & $0.52(0.34)$ & $0-1$ & $0.33(0.43)$ & $0.67(0.83)$ & \\
\hline Intelligibility & $0.83(0.15)_{\mathrm{a}}$ & $0.79(0.12)_{\mathrm{a}}$ & $0.37(0.27)_{\mathrm{b}}$ & $0-1$ & $-1.07(0.43)$ & $0.47(0.83)$ & 17.22 \\
\hline \multicolumn{8}{|l|}{ Observations } \\
\hline Positive Affect & $0.28(0.23)$ & $0.38(0.21)$ & $0.17(0.17)$ & $0.00-0.73$ & $0.36(0.43)$ & $-1.03(0.83)$ & \\
\hline Negative Affect & $0.03(0.05)$ & $0.02(0.05)$ & $0.01(0.02)$ & $0.00-0.18$ & $2.99(0.43)$ & $8.90(0.83)$ & \\
\hline Neutral Affect & $0.69(0.21)$ & $0.60(0.19)$ & $0.82(0.17)$ & $0.28-1.00$ & $-0.26(0.43)$ & $-0.89(0.83)$ & \\
\hline
\end{tabular}

Note. All $F$ values are significant at $p<.01$. Means in the same row with different subscripts are significantly different. PPVT = Peabody Picture Vocabulary Test; EVT = Expressive Vocabulary Test; MLUm = mean length of utterance; MLT = mean length of turn; Intelligibility = proportion of intelligible utterances 
Descriptive findings for the child with a disability and typically developing sibling measures are presented in Tables 3 and 4 . Visual inspection of these data and dividing the skew statistic by its associated standard error (with a resulting score greater than two) found that three child variables and one sibling variable exhibited significant deviations from normality. These variables included child mean length of utterance in morphemes (MLUm), child and sibling mean length of turn (MLT), and child proportion of intelligible utterances. To address these significant deviations from normality in the analyses, these variables were transformed utilizing the procedures described by Tabachnick and Fidell (2007). Child MLU exhibited slightly positive skew and a square root transformation was applied. Although this transformation brought the distribution closest to normal, analyses produced the same results regardless of whether MLUm was transformed or untransformed. Therefore the untransformed MLUm was used in all analyses. Both sibling and child mean length of turn (MLT) exhibited significant positive skew. For sibling MLT, none of the three transformation procedures were able to bring the variable to a normal distribution due to the presence of two univariate outliers. Tabachnick and Fidell (2007) suggest reassigning the offending cases to a score that is one unit larger than the next most extreme score in the distribution. When these two cases were reassigned, a square root transformation of both variables brought them closest to a normal distribution. Child proportion of intelligible utterances exhibited significant negative skew. The inverse transformation was applied and brought the distribution closest to a normal distribution. As with MLUm, analyses using proportion of intelligible utterances produced the same result regardless of whether it was transformed or untransformed. Therefore, the untransformed variable was used for all analyses. 
The observational measures of negative affect for both the sibling and the child were severely negatively skewed due to substantial floor effects indicating that neither member of the dyad exhibited many negative behaviors. Rather than transform these variables, the variable was dichotomized. An absence of negative behavior present was coded as zero and any negative behavior present was coded as one.

Table 4

Descriptive Statistics for Typically Developing Sibling

\begin{tabular}{lcccc} 
Variable & $\mathrm{M}(\mathrm{SD})$ & Range & Skew & Kurtosis \\
\hline $\begin{array}{l}\text { Communication Interaction } \\
\text { Measures }\end{array}$ & & & & \\
$\quad$ & & & & \\
$\quad$ MLUm & $4.52(0.83)$ & $2.92-6.76$ & $0.67(0.43)$ & $1.56(0.83)$ \\
MLT & $10.22(5.99)$ & $5.54-18.56$ & $0.94(0.43)$ & $0.22(0.83)$ \\
$\quad$ Type Token Ratio & $0.33(0.09)$ & $0.21-0.59$ & $0.87(0.43)$ & $0.50(0.83)$
\end{tabular}

Observation Measures

$\begin{array}{lllll}\text { Positive Affect } & 0.33(1.72) & 0.03-0.69 & 0.12(0.43) & -0.22(0.83) \\ \text { Negative Affect } & 0.01(0.03) & 0.00-0.18 & 5.32(0.43) & 28.67(0.83) \\ \text { Neutral Affect } & 0.67(0.16) & 0.31-0.95 & -0.23(0.43) & -0.14(0.83)\end{array}$

SRQ-R Factor Scores

\begin{tabular}{lcccc} 
Warmth/Closeness & $3.37(0.57)$ & $2.52-4.90$ & $0.76(0.43)$ & $0.47(0.83)$ \\
Relative Status/Power & $1.19(0.97)$ & $-0.83-4.33$ & $1.08(0.43)$ & $2.93(0.83)$ \\
Conflict & $2.73(0.79)$ & $1.44-4.67$ & $0.54(0.43)$ & $-0.13(0.83)$ \\
Rivalry & $-1.33(1.50)$ & $-1.33-1.50$ & $0.85(0.43)$ & $3.38(0.83)$ \\
\hline
\end{tabular}

Note. $N=30$; All variables are untransformed; MLUm = Mean Length of Utterance in morphemes; MLT = Mean Length of Turn; SRQ-R = Sibling Relationship Questionnaire Revised 


\section{Characteristics of Communication Interaction Patterns:}

The first research question asked about the characteristics of siblings' communication patterns for sibling dyads that included a child with a disability. Three mixed between-within subjects ANOVA's were used to examine the characteristics of sibling's communication interaction patterns for sibling dyads that included a child with a disability. The within-subjects variable was the dyad (typical sibling, sibling with a disability) and the between-subjects variable was communication status of the child with the disability (independent, context-dependent, and emerging). The dependent variables for each analysis were MLUm, MLT(sqrt), and type token ratio, respectively. For analyses involving dyads, there is the concern that one member of the dyad may influence the response of the other member of the dyad, making the responses nonindependent. Assessing independence of observations depends on whether members of the dyad are distinguishable or exchangeable (Kenny, Kashy, \& Cook, 2006). For this study, the members of each dyad are distinguishable such that one member of the dyad is always the older typically developing sibling and the other member is always the younger child with a disability. Therefore the Pearson correlation was used to assess independence of observations. For this sample, the correlations between dyads for MLUm, MLT(sqrt), and type token ration were $r=-0.21,-0.04$, and -0.10 , respectively. These correlations were all negative and nonsignificant indicating that the two members responded differently and were independent (Kenny et al., 2006).

Data met all general linear model assumptions of homogeneity of variance and independence. Although child MLUm deviated from normality, this variable was kept in the analysis in it's original form as described previously. The first analysis for MLUm revealed 
significant main effects for dyad, $F(1,27)=97.27, p<.05, p \eta^{2}=0.78$, and communication status, $F(2,27)=11.68, p<.05, p \eta^{2}=0.46$. There was a significant interaction between dyad and communication status for MLUm, $F(2,27)=4.35, p<.05, p \eta^{2}=0.24$. To interpret this interaction, a simple effects analysis was conducted to determine what accounted for the differences. Paired-samples t-tests indicated that for children with disabilities who were independent communicators, there were no significant differences between the siblings for MLUm, $t(1,8)=-1.97, p>.05$. There were significant differences between siblings when the child with a disability was a context-dependent communicator, $t(1,10)=-8.74, p<0.01$, and when the child with a disability was an emerging communicator, $t(1,9)=-7.10, p<0.01$. Additionally, Tukey post hoc tests indicated that although typically developing siblings exhibited decreases in MLU based on the communication status of their sibling, these differences were not significant. For the children with disabilities, all three communication status groups differed from each other with independent communicators exhibiting the highest $\operatorname{MLU}(M=3.84, S D=$ $1.07)$, followed by context-dependent $(M=2.20, S D=0.57)$, and emerging communicators $(M=$ $1.29, S D=0.53)$. This interaction is shown in Figure 1 where $\mathrm{I}=$ independent communicators, $\mathrm{CD}=$ context-dependent communicators, and $\mathrm{E}=$ emerging communicators. 
Figure 1

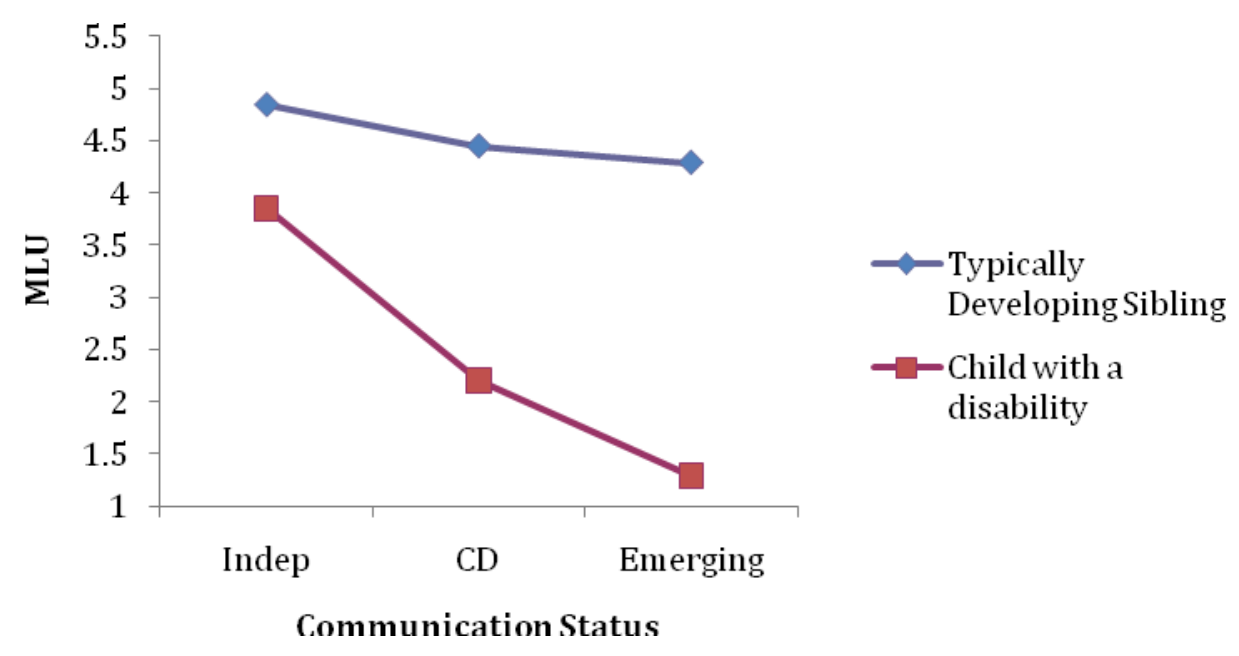

The analysis for MLT (sqrt) revealed a significant main effect for dyad, $F(1,27)=$ 126.33, $p<0.001, p \eta^{2}=0.82$, but not for communication status, $F(2,27)=3.00, p>0.05, p \eta^{2}=$ 0.19 , on MLT(sqrt). The interaction between dyad and communication status was not significant, $F(2,27)=1.84, p>.05, p \eta^{2}=0.12$. Regardless of the child's communication status, typically developing siblings ( $M=3.31, S D=0.53$ ) exhibited a higher mean length of turn than their sibling with a disability $(M=1.89, S D=0.38)$.

The analysis for type token ratio revealed a significant main effect for dyad, $F(1,27)=$ 14.02, $p<0.01, p \eta^{2}=0.34$, but not for communication status, $F(2,27)=0.45, p>0.05, p \eta^{2}=$ 0.03. The interaction between dyad and communication status was not significant, $F(2,27)=$ $0.06, p>0.05, p \eta^{2}=0.01$. Children with disabilities $(M=0.51, S D=0.22)$ exhibited a higher type token ratio than their typically developing siblings $(M=0.33, S D=0.09)$. 


\section{Sibling Relationship Quality}

The second question asked if sibling relationship quality measured by a) self-report and b) observation, was impacted by the communication status of the child with the disability. A one-way between-subjects multivariate analysis of variance (MANOVA) was performed to address this question. The dependent variables were the four subscales of the Sibling Relationship Questionnaire: Warmth/Closeness, Relative Status/Power, Conflict, and Rivalry. The independent variable was communication status of the child with a disability. Preliminary assumption testing was conducted to check for normality, linearity, univariate or multivariate outliers, homogeneity of variance-covariance matrices, and multicollinearity, with no serious violations noted. Means and standard deviations are shown in Table 5.

The results revealed a significant multivariate effect for communication status on the combined dependent variables, $F(4,25)=2.10, p<.05, p \eta^{2}=0.27$, Pillai's Trace $=.53$. Pillai's criterion was used in this analysis due to the small sample size and unequal N's in each group (Tabachnick and Fidell, 2007). When the results for the dependent variables were considered separately, there were no significant differences between groups on measures of warmth/closeness, $F(2,27)=1.67, p>0.05, p \eta^{2}=0.11$, conflict, $F(2,27)=2.21, p>0.05, p \eta^{2}$ $=0.14$, or rivalry, $F(2,27)=2.80, p=.07, p \eta^{2}=0.17$. The only difference to reach statistical significance was relative status/power, $F(2,27)=3.43, p=0.04, p \eta^{2}=0.20$. Tukey post-hoc tests indicated that all three groups were significantly different from each other. Siblings of children who were independent communicators reported significantly higher levels of relative status/power $(M=2.85, S D=0.76)$ compared to context-dependent $(M=2.05, S D=0.67)$ and emerging communicators $(M=1.53, S D=0.46)$. Context-dependent and emerging communicators were also significantly different. 
Two one-way ANOVA's were used to address how communication status impacted observational measures of positive and neutral affect for the typically developing sibling. Only two of the thirty siblings exhibited any negative behaviors during the ten-minute interaction.

Due to this lack of variability, this variable was not analyzed. Results indicated that there were no significant differences between communication status groups for positive or neutral affect, $F$ $(2,29)=0.30, p>0.05, p \eta^{2}=0.02$, and $F(2,29)=0.60, p>0.05, p \eta^{2}=0.04$, respectively Table 5

Means and SDs of Sibling Relationship Variables by Communication Status Group

Independent Context-dependent Emerging

$(\mathrm{n}=9) \quad(\mathrm{n}=11) \quad(\mathrm{n}=10)$

\begin{tabular}{|c|c|c|c|c|}
\hline Variable & $M(S D)$ & $\mathrm{M}(\mathrm{SD})$ & $\mathrm{M}(\mathrm{SD})$ & $\begin{array}{c}F \text { test group } \\
\text { difference }\end{array}$ \\
\hline
\end{tabular}

Sibling Relationship

Questionnaire

$\begin{array}{lcccc}\text { Warmth/Closeness } & 3.10(0.40) & 3.55(0.64) & 3.41(0.57) & 1.67 \\ \text { Conflict } & 2.96(0.53) & 2.90(1.01) & 2.32(0.57) & 2.21 \\ \text { Rivalry } & 3.22(0.46) & 2.91(0.61) & 2.67(0.43) & 2.80 \\ \text { Relative Status } & 2.85(0.76)_{\mathrm{a}} & 2.05(0.67)_{\mathrm{b}} & 1.53(0.46)_{\mathrm{c}} & 3.43^{*}\end{array}$

Observed Behavior

$\begin{array}{llll}\text { Positive } & 0.32(0.16) & 0.36(0.20) & 0.30(0.15)\end{array} \quad 0.30$

Neutral $\quad 0.68(0.16) \quad 0.63(0.18) \quad 0.70(0.15) \quad 0.60$

Note. Means in the same row with different subscripts are significantly different. $* p=.05$ 
Prediction of Sibling Relationship Quality by Vocabulary and Interaction Measures:

The third question examined if aspects of vocabulary and communication interaction measures predicted self-reported measures of sibling relationship quality. Four standard multiple regression analyses were performed. Factor scores for the four factors from the Sibling Relationship Questionnaire were used as the dependent variables and PPVT raw score, MLUm, and the proportion of intelligible utterances as predictor variables. The bivariate correlations among the independent variables are presented in Table 6. Variables met the multiple regression assumptions of outliers, homoscedasticity of residuals, linearity, and multicollinearity. Although child MLUm and proportion of intelligible utterances deviated from normality, this variable was kept in the analysis in it's original form as described previously. These predictor variables were all significantly correlated but the collinearity diagnostics were all within the acceptable range. Table 6

Bivariate Correlations of the vocabulary and communication interaction measures

Variable $\quad 1 \quad 2 \quad 3$

\section{PPVT Raw Score}

2. Child MLUm $0.75 \quad-$

3. Child Intelligibility $0.520 .68 \quad-$

Note: Child MLU = mean length of utterance in morphemes; Intelligibility= proportion of intelligible utterances.

Results of the four multiple regression analyses with simultaneous entry are presented in Tables 7-10. The child measures of PPVT, MLUm, or proportion of intelligible utterances did 
not significantly predict warmth/closeness, $F(3,26)=0.27, p>.05, R^{2}=0.03$, conflict $F(3,26)$ $=1.90, p>.05, R^{2}=0.18$, relative status/power, $F(3,26)=2.4, p>.05, R^{2}=0.22$, or rivalry, $F$ $(3,26)=2.60, p>.05, R^{2}=0.23$, as reported by siblings. Although none of the omnibus tests were significant, the individual effects were interpreted because the effect sizes for relative status/power and rivalry were moderate as $22 \%$ of the variance in relative status/power and $23 \%$ of the variance in rivalry were accounted for by the predictors in the model.

As seen in Table 8, the PPVT raw score was a significant predictor of relative status/power indicating that siblings of children who had greater receptive vocabulary scores reported greater levels of relative status/power in their relationship with their sibling. Additionally, as seen in Table 10 the proportion of intelligible utterances was a significant predictor of rivalry indicating that children whose utterances were more intelligible had siblings who reported lower amounts of rivalry in the relationship.

Table 7

Prediction of Warmth/Closeness by vocabulary and communication interaction measures

$95 \% \mathrm{CI}$

\begin{tabular}{lccccc} 
Variable & $B$ & $\beta$ & Lower & Upper & $p$ \\
\hline PPVT Raw & & & & & \\
\\
MLU & 0.00 & -0.01 & -0.01 & 0.01 & 0.97 \\
& -0.41 & -0.25 & -1.71 & 0.88 & 0.52 \\
Proportion of intelligible utterances & & & & & \\
\hline
\end{tabular}
Note. $F(3,26)=0.33, R^{2}=0.03$ 
Table 8

Prediction of Relative Status/Power by vocabulary and communication interaction measures

\section{$95 \% \mathrm{CI}$}

\begin{tabular}{lccccc} 
Variable & $B$ & $\beta$ & & & $p$ \\
\hline & & & & & \\
PPVT Raw & 0.03 & 0.59 & 0.00 & 0.05 & $0.05^{*}$ \\
MLU & -2.33 & -0.54 & -5.41 & 0.74 & 0.13 \\
& & & & & \\
Proportion of intelligible utterances & -3.74 & -0.35 & -8.93 & 1.46 & 0.15 \\
\hline
\end{tabular}

Note. $F(3,26)=2.28, R^{2}=0.22$

Table 9

Prediction of Conflict by vocabulary and communication interaction measures

$95 \% \mathrm{CI}$

\begin{tabular}{lccccc} 
Variable & $B$ & $\beta$ & & $p$ \\
PPVT Raw & -0.01 & -0.17 & -0.02 & 0.01 & 0.59 \\
MLU & 0.30 & 0.13 & -1.36 & 1.95 & 0.72 \\
& & & & & \\
Proportion of intelligible utterances & -2.27 & -0.41 & -5.07 & 0.53 & 0.11 \\
\hline
\end{tabular}

Note. $F(3,26)=1.86, R^{2}=0.18$ 
Table 10

Prediction of Rivalry by vocabulary and communication interaction measures

$95 \% \mathrm{CI}$

\begin{tabular}{lccccc} 
Variable & $B$ & $\beta$ & & & $p$ \\
\hline PPVT Raw & 0.00 & -0.13 & -0.01 & 0.01 & 0.65 \\
MLU & 0.16 & 0.10 & -0.95 & 1.26 & 0.77 \\
& & & & & \\
Proportion of intelligible utterances & -0.96 & -0.49 & -0.67 & -1.85 & $0.04 *$ \\
\hline
\end{tabular}

$F(3,26)=2.60, R^{2}=0.23$

Relation of Observed Affective Quality to Self-Reported Sibling Relationship Quality

The fourth question examined how affective quality as measured in the observation correlated with self-reported measures of sibling relationship quality. It was expected that these correlations would be low and in general, this hypothesis was supported. As a whole, correlations were generally low between both child and sibling observational measures of affect and dimensions of sibling relationship quality reported by the typical sibling. Non-significant correlations ranged from $r=-0.30$ to $r=0.28$. There was a significant negative correlation between negative affect observed for the child and warmth/closeness for the sibling, $r=-0.403, p$ $=0.03$. This correlation indicates that children with disabilities who engaged in more negative behavior during the observation had siblings who reported lower feelings of warmth and closeness.

Typically Developing Siblings Perceptions of Their Sibling's Communication Skills

This question examined non-disabled siblings' perceptions of their sibling's communication skills based on the SCQ. These results are summarized in Table 11. Section A describes the results of the Likert style questions. Chi-square tests were used to determine if 
groups were more likely to answer questions in a particular way. Only one chi-square analysis was significant. For the question "How would you describe your sibling's communication skills", a chi-square analysis was significant $\chi^{2}(6, N=30)=17.78$, indicating that siblings of independent communicators were more likely to indicate that everyone understood what they were saying, while siblings of context-dependent and emerging communicators were more likely to say that their siblings tried to communicate but people outside of the family did not understand what they were saying.

Section B of Table 11 describes results of the multiple choice questions. For the question, "What do you see as your primary role in your sibling's day to day life", many of the siblings indicated that they saw their primary role as helper and playmate and did not feel that they could distinguish between the two. Therefore they were instructed them to circle both and "helper and playmate" was added as a separate category for analysis. For the children who did not indicate any of the answers, typical siblings wrote responses such as "I'm a brother and that entitles all of the above", while another sibling wrote, "friend".

For the question, "In what ways do you and your sibling communicate with each other", the choices were "speech", "gestures/manual sign", "speech-generating device (SGD)", "does not communicate", and "other". Siblings were told that they could answer in more than one way. For the purposes of this study, gestures and SGD were combined as well as speech and gestures. For the $3.3 \%$ of the siblings who reported "other", they indicated that they communicated with their sibling through yelling and screaming. No one reported that they did not communicate with their sibling with a disability. It should also be noted that although parents reported that four children with disabilities used an SGD to varying degrees of implementation, only one sibling reported using an SGD to communicate with their sibling with a disability. 
Section $\mathrm{C}$ describes the open-ended questions. For the question, "Tell me a little about your sibling. What do I need to know about him/her", the responses fell into categories relating to their sibling with a disability's communication skills, disability, personality characteristics, and things they liked to do. For communication skills of the child with a disability, siblings answered with responses such as, "I have to translate her", "She can't talk", and "He can't talk well so he uses his actions to tell me how he feels". For disability, siblings answered with responses such as, "He does not have mental problems, just CP", and "He has Down syndrome so he loves to talk and follow me around and do everything I do". For problems related to having a sibling with a disability they answered with responses such as, "She hates not getting her way, she will get her way. She will make you think she is vulnerable and innocent and that you need to serve her", "He is very affectionate but sometimes he can be very embarrassing. He kicks, screams, and hits people when he is angry", and "Great little brother but sometimes can be stubborn and difficult". For personality characteristics of their sibling with a disability they answered with responses such as, "She is playful and energetic", "He has a great memory", "He is very funny. He likes to build and is inventive", "She is very unique", and "She is super bright and loves to joke around". Finally, some siblings talked about the things that their sibling with a disability liked to do with responses such as, "He likes to watch TV, play video games, and help dad outside". Two siblings chose not to answer.

For the question, "What kinds of things do you help your sibling need with", the typically developing sibling answered with responses pertaining to speech and communication; day-to-day skills such as getting dressed, fixing food, taking a bath; sports-related activities; reading and homework; socializing; and finally behavior, such as being less aggressive and not so mean. Finally, one reported that their sibling needed help with "everything" 
For the question, "What kinds of things do you like to do with your sibling", the typically developing sibling answered with responses pertaining to playing outside, playing video games such as Wii, playing with toys, playing sports, reading books, and watching TV. Some children also responded that they liked to eat and cook with their sibling with a disability. One sibling responded that she and her sister liked to dance together. 
Table 11

Sibling Communication Questionnaire; Item Level Responses

\begin{tabular}{|c|c|c|c|c|c|}
\hline \multirow[t]{2}{*}{ Item } & \multirow[t]{2}{*}{ Response Category } & \multicolumn{3}{|c|}{ Group } & $\chi^{2}$ \\
\hline & & $\mathrm{I}$ & $\mathrm{CD}$ & $\mathrm{E}$ & \\
\hline \multicolumn{6}{|l|}{ Section A } \\
\hline \multirow{3}{*}{$\begin{array}{l}\text { My sibling is a very important } \\
\text { person in my life. }\end{array}$} & Strongly Agree: & 0.66 & 0.73 & 0.67 & 2.46 \\
\hline & Agree: & 0.33 & 0.27 & 0.22 & \\
\hline & No opinion: & - & - & 0.11 & \\
\hline \multirow{3}{*}{$\begin{array}{l}\text { How well do you understand } \\
\text { what your sibling is saying? }\end{array}$} & All the time: & 0.44 & 0.18 & 0.20 & 4.02 \\
\hline & Most of the time: & 0.56 & 0.82 & 0.70 & \\
\hline & Sometimes: & - & - & 0.10 & \\
\hline \multirow{5}{*}{$\begin{array}{l}\text { My relationship with my sibling } \\
\text { would be different if he/she had } \\
\text { different communication skills. }\end{array}$} & Strongly Agree: & 0.11 & 0.55 & 0.20 & 3.77 \\
\hline & Agree: & 0.56 & 0.18 & 0.50 & \\
\hline & Disagree: & 0.11 & 0.18 & 0.10 & \\
\hline & Strongly Disagree: & 0.22 & 0.09 & 0.10 & \\
\hline & No opinion: & - & - & 0.10 & \\
\hline \multirow{3}{*}{$\begin{array}{l}\text { How would you describe your } \\
\text { sibling's communication skills? }\end{array}$} & Everyone understands: & 0.44 & 0.09 & - & $17.78 *$ \\
\hline & Family understands: & 0.56 & 0.91 & 0.90 & \\
\hline & Does not talk much: & - & - & 0.10 & \\
\hline \multicolumn{6}{|l|}{ Section B } \\
\hline \multirow{5}{*}{$\begin{array}{l}\text { What do you see as your } \\
\text { primary role in your sibling's } \\
\text { day-to-day life? }\end{array}$} & Helper: & 0.11 & 0.27 & 0.40 & N/A \\
\hline & Babysitter: & 0.11 & 0.09 & - & \\
\hline & Playmate: & 0.11 & 0.09 & - & \\
\hline & Helper and Playmate: & 0.56 & 0.55 & 0.50 & \\
\hline & Other (all; a friend): & 0.11 & - & 0.10 & \\
\hline \multirow{4}{*}{$\begin{array}{l}\text { In what ways do you and your } \\
\text { sibling communicate with each } \\
\text { other }\end{array}$} & Speech: & 1.00 & 0.82 & 0.50 & N/A \\
\hline & Gestures/sign/SGD: & - & 0.09 & 0.40 & \\
\hline & Gesture/sign/speech: & - & 0.09 & 0.10 & \\
\hline & Other: & - & - & - & \\
\hline \multicolumn{6}{|l|}{ Section C } \\
\hline \multirow{5}{*}{$\begin{array}{l}\text { Tell me a little about your } \\
\text { sibling. What do I need to } \\
\text { know about him or her? }\end{array}$} & Communication Skills: & - & 0.09 & 0.30 & N/A \\
\hline & Disability: & - & 0.18 & 0.10 & \\
\hline & Problems: & 0.44 & 0.27 & 0.10 & \\
\hline & Personality: & 0.33 & 0.27 & 0.20 & \\
\hline & Likes: & 0.22 & 0.09 & 0.20 & \\
\hline \multirow{7}{*}{$\begin{array}{l}\text { What kinds of things do you } \\
\text { help your sibling with? }\end{array}$} & Speech/Communication: & 0.11 & 0.18 & 0.50 & $\mathrm{~N} / \mathrm{A}$ \\
\hline & Day-to-Day skills: & 0.11 & 0.45 & 0.40 & \\
\hline & Sports: & - & 0.09 & - & \\
\hline & Reading/Homework: & 0.33 & 0.18 & - & \\
\hline & Behavior: & 0.22 & 0.09 & - & \\
\hline & Socializing: & 0.22 & - & - & \\
\hline & Everything: & - & - & 0.10 & \\
\hline
\end{tabular}




\begin{tabular}{llcccc}
\hline What kind of things do you like & All & 0.11 & 0.64 & 0.30 & N/A \\
to do with your sibling? & Play outside games TV & 0.44 & 0.09 & 0.20 & 0.20 \\
& Games toys TV & 0.33 & 0.09 & 0.10 \\
& Sports books TV & 0.11 & - & - & - \\
& None & - & 0.09 & 0.20 \\
\hline
\end{tabular}

Note. $\mathrm{I}=$ Independent Communication Group, $\mathrm{CD}=$ Context-dependent Communication Group, $\mathrm{E}=$ Emerging Communication Group.

\section{Discussion}

The purpose of this study was to examine the characteristics of sibling communication interaction patterns when one sibling had an intellectual or developmental disability and the unique role that communication skill played in the quality of the sibling relationship. Current literature has identified variables such as personality and temperament, level of competence, health problems and secondary disabilities as etiological factors that could influence the relationship between children with disabilities and their typically developing siblings (Stoneman, 1998). This is the first study to date that has examined the unique role of communication skills by not only grouping children with disabilities according to communication status but also by examining aspects of communication that predict dimensions of sibling relationship quality.

\section{Characteristics of Communication Interaction Patterns}

The first question examined the characteristics of siblings' communication patterns for sibling dyads that included a child with a disability. It was hypothesized that typically developing siblings of children with disabilities would play a more dominant role in the interaction and that this effect would be moderated by the communication status of the children with disabilities. Specifically, siblings of children with disabilities would exhibit higher MLUm, longer MLT, and higher type token ratio than their sibling with a disability and that this would be moderated by the communication status of the children with disabilities. This hypothesis was 
partially supported. For MLUm, results indicated that there were no significant differences between sibling dyads when the child with a disability was an independent communicator but there were significant differences for both context-dependent and emerging communicators. MLUm is a measure of lexical complexity such that the greater the MLU, the greater morphological and syntactic skills that the child has. Children with disabilities who are independent communicators exhibit interactions with their siblings that are comparable in terms of lexical complexity while those who are context-dependent and emerging communicators exhibit significantly less sophisticated morphological and syntactic skills. Although not statistically significant, typically developing siblings exhibited slight decreases in their MLUm slightly when their siblings were context-dependent and in emerging communicators. For the children with disabilities who had less sophisticated morphological and syntactic skills, their siblings seemed to adjust their MLUm to a level that was appropriate for their interaction.

For MLT, results supported the hypothesis that typically developing siblings would dominate the interaction but this effect was not moderated by communication status. Regardless of communication status, typically developing siblings exhibited a longer mean turn length than their sibling with a disability. This indicated that the typically developing siblings were using more consecutive utterances than their sibling with a disability. This suggests that the typical siblings were dominating the interaction by speaking more often and longer than their sibling with a disability. Whereas independent communicators and their siblings were comparable in terms of lexical complexity, they were not comparable in terms of being equal communicative partners in the interaction.

For type token ratio, the hypothesis was not supported and in fact results were opposite than what was predicted. Regardless of communication status, children with disabilities 
exhibited a higher type token ratio than their typically developing siblings. Type token ratio is a measure of lexical variation in speech. This ratio was calculated by dividing the number of different words (types) by the total number of words spoken (tokens). The fact that children with disabilities exhibited a greater amount of lexical variety could be a reflection of the task selected for the interaction itself rather than an inherent difference between typically developing children and their siblings with disabilities. The children engaged in a task that involved making a snack together, specifically decorating cookies with icing and sprinkles. There was not a lot of opportunity to talk about or discuss other things which may have resulted in less lexical variety. The difference in type token ratio could suggest that the typically developing siblings tended to keep the topic of the conversation on the task at hand while the children with disabilities would bring other topics into the conversation.

As a whole, these results are both consistent with and extend what we know about sibling interactions for children who have disabilities and difficulties with communication.

Observational studies of sibling interaction have shown that generally speaking, children with disabilities take a less active role in the interaction due to difficulty facilitating and initiating interaction (Abramovitch et al., 1987; Dallas, Stevenson, \& McGurk, 1993; Knott et al., 1995). This finding is true of the current study. Typically developing siblings engaged in longer conversational turns than their sibling with a disability regardless of communication status, which indicated their dominance of the interaction with less reciprocation by the child with a disability.

The current study also found that when children with disabilities were independent communicators, they were comparable in terms of lexical complexity to their typical siblings. However, this was not the case for context-dependent and emerging communicators who 
exhibited lower MLU and whose typical siblings also exhibited lower MLU depending on the communication status of their sibling with a disability. Observational studies of sibling interactions for children with disabilities have shown that typically developing siblings adjust their level of play depending on the competencies of their sibling with a disability (Stoneman et al., 1987), but no study until this one has examined whether siblings adjust their language within the interaction. For parent-child interactions for children with disabilities, research has shown that parents change the complexity of their language to match their children as a function of their children's communication status. Specifically, they adjust their language based on their children's level of linguistic competence (Pellegrini, Brody, \& Sigel, 1985). It could follow that siblings of children with disabilities may adjust their language in a similar way.

\section{Sibling Relationship Quality}

The second question investigated the effect of communication status on measures of sibling relationship quality. It was expected that typically developing siblings of emerging communicators would report lower levels of warmth/closeness and conflict, but greater levels of rivalry and relative status/power, as compared to both context-dependent and independent communicators. This hypothesis was not supported. There were no significant differences between the groups on warmth/closeness or conflict. Regardless of communication status, typically developing siblings rated their relationship with their sibling as being low in conflict and above average on warmth and closeness. This is consistent with previous studies for children with disabilities that have used the SRQ and found that sibling relationships are generally positive and low in conflict (Begun, 1989; Cuskelly \& Gunn, 2003; Kaminsky \& Dewey, 2001; McHale \& Gamble, 1989). 
For relative status/power, all three communication status groups were significantly different from each other with siblings of independent communicators reporting higher status for themselves followed by context-dependent and emerging communicators. This result was opposite to what was predicted. This factor is a measure of the symmetry in the sibling relationship. Higher scores on this factor indicate that the typically developing sibling has higher status in the relationship relative to their sibling with a disability. Specifically, a high score on this factor indicated that the typically developing sibling engaged in more helping, teaching, and managing behaviors while the sibling with a disability engaged in relatively lower amounts of these same behaviors towards the typical sibling, thus making the relationship more asymmetrical. Current literature indicates that this asymmetry is one of the main differences between typical sibling relationships and those involving individuals with disabilities (Abramovitch et al., 1987; Stoneman, 2001; Stoneman et al., 1989). In a review of their work, Stoneman and Brody (1993) indicated that children with disabilities who have greater cognitive and linguistic competencies tend to exhibit more symmetrical relationships. Therefore, one might expect that the typical sibling would need to engage in more helping and teaching behaviors with a child who has more difficulty with communication. However, in this study, the typical siblings reported higher relative status for themselves when the child with a disability had better communication skills. This is opposite to what has been found in the literature. Although Stoneman, Brody, Davis, and Crapps (1987) found high levels of interaction among the sibling dyads in their sample, it could be that when the child with a disability exhibits more difficulty with communication, they spend less time interacting with their typically developing sibling. When the child with a disability is independent in their communication, they may spend more time with their typically sibling and there is more opportunity to engage in these types of 
helping, teaching, and managing behaviors. Although it is not possible to compare this to previous literature, as this is the only study to date that has grouped children based on communication, one study found that language ability was predictive of the amount of play between siblings and could explain this finding (Stoneman, et al., 1987).

For the observational measures of affective quality, results indicated that there were no group differences and that the interactions were largely neutral and positive. The reason for the largely neutral nature of the interaction could be due to the fact that the typically developing sibling engaged in the same helping, teaching, and managing behaviors during the interaction. These types of behaviors can be considered directive. In the literature examining interactions in typical sibling dyads, these types of behaviors are considered negative. This is not always the case however, for sibling dyads that include a child with a disability (Floyd, Purcell, Richardson, $\&$ Kupersmidt, 2009). The finding that the typically developing siblings engaged in very few negative behaviors is also consistent with previous literature indicating that interactions between these siblings are very rarely characterized by negative affect and behaviors (Brody et al., 1991; Stoneman et al., 1987; Stoneman et al., 1991).

\section{Prediction of Sibling Relationship Quality by Vocabulary and Interaction Measures}

The third question examined aspects of vocabulary and communications interaction measures that predicted dimensions of sibling relationship quality regardless of communication status. It was expected that children who performed at a higher level on a measure of vocabulary ability and transcript interaction measures would report higher levels of warmth/closeness, conflict, and lower levels of relative status/power and rivalry. Overall this hypothesis was not supported, as none of the omnibus tests were significant. This analysis may have been underpowered and there were significant findings for individual predictors that are important to 
discuss. Children with disabilities who had higher receptive vocabulary raw scores on the PPVT had typically developing siblings who reported greater levels of relative status/power for themselves in their relationship. The PPVT was chosen as a predictor variable in these analyses because of previous research indicating that it distinguished between different groups of communicators (Romski \& Sevcik, 1996). Similarly, it distinguished between all three communication groups in the current study. As with the findings from the second question, children who have better receptive vocabulary skills may be more likely to spend greater amounts of time around their typical siblings which would lead to the typical sibling engaging in more teaching, helping, and managing behaviors.

The finding that children with disabilities who had more intelligible utterances in the interaction had siblings who reported lower levels of rivalry in the sibling relationship is interesting. When children with disabilities were more intelligible, the typical siblings in this study perceived that their parents treated them equally in terms of the amount of attention given and who was favored. The converse is also true, that children who were less intelligible had siblings who perceived greater amounts of parental partiality towards their sibling. Current literature in this area is mixed with some studies indicating that typical siblings of children with disabilities report greater parental partiality (McHale et al., 1986; Stoneman, 2005); while others do not (Kaminsky \& Dewey, 2001). It makes sense that typical siblings of children with disabilities who have greater difficulties with communication may perceive that their parents are giving more attention to and favoring their sibling with a disability. However, in the disability literature, reporting more parental partiality towards the sibling with a disability does not necessarily mean that they also report less warmth and closeness. Parental partiality may be interpreted as a justified parent response to the greater caretaking needs of the child with a 
disability rather than favoritism (Stoneman, 1998). The same is true for this sample, as warmth/closeness and rivalry were not highly correlated $(r=0.12)$. Relation of Observed Affective Quality to Self-reported Sibling Relationship Quality

The fourth question examined correlations between a self-report measure of sibling relationship quality and observational measures of affect. It was expected that there would be low correlations between these self-report and observational measures. Overall, this hypothesis was supported as generally low correlations between these measures were observed. Previous research has suggested that it is important to examine both self-report and observation measures because often typically developing siblings often rate their relationships more positively on selfreport measures than what is observed during actual interaction (Rossiter \& Sharpe, 2001). This is supported by the current findings. Although the typically developing siblings reported generally positive relationships with their siblings with a disability, the actual interactions were primarily neutral. On average, typically developing siblings engaged in positive behaviors $33 \%$ of the time spent in the ten-minute interaction. There could be several reasons for this finding. First, the finding could be an artifact of the videotaped interaction. The typically developing siblings could have felt self-conscious with the video camera and did not engage in behavior that would be typical of their day-to-day interaction with their sibling with a disability. Alternatively, it could be that their actual interactions are neutral even when the camera is present. As discussed previously, although using more commands and directives are not considered negative behaviors for siblings of children with disabilities, they necessarily reduce the proportion of the interaction that is rated as positive.

The significant negative correlation between negative affect observed for the child with a disability and warmth/closeness for the sibling indicated that children with disabilities who 
engaged in more negative behavior during the observation had siblings who reported lower levels of warmth and closeness. Although there is some literature to suggest that behavior problems in children with disabilities can have a negative impact on the psychosocial adjustment of the typical siblings (Neece, Blacher, \& Baker, 2010; Pilowsky et al., 2004) there is surprisingly, very little literature to date that examines the impact on the sibling relationship itself.

Typically Developing Siblings Perceptions of Their Sibling's Communication Skills

The final question explored features that characterized non-disabled siblings' perceptions of their sibling's communication skills. It was hypothesized that siblings of independent communicators would answer questions differently than siblings of context-dependent or emerging communicators. As a whole, this hypothesis was not supported. Typical siblings tended to answer questions the same regardless of the communication status of the children with disabilities. The only significant difference between the groups was for the question that asked the typically developing siblings to describe their sibling's communication skills. Siblings of independent communicators were more likely to indicate that everyone understood what they were saying, while siblings of context-dependent and emerging communicators were more likely to say that their siblings tried to communicate but people outside of the family did not understand what they were saying.

Typical siblings did not differ on the questions related to how important they felt their sibling was to them, how their relationship would be different if their sibling had different communication skills, or how well they understood what their sibling was saying. The overwhelming majority (92\%) of the typically developing siblings agreed or strongly agreed that their sibling with a disability was a very important person in their life. This is consistent with 
current literature indicating that most typically developing siblings feel very strongly about their sibling with a disability and report that having a sibling with a disability has led to increased opportunities for maturity, empathy, and growth (Dykens, 2005; Hannah \& Midlarsky, 2005). Interestingly, a majority (63\%) of these siblings also felt that their relationship with their sibling would be different if their brother or sister had different communication skills. While the typical siblings felt that their sibling with a disability was an important person in their life, they also acknowledged that difficulties with communication made their relationship different than what might be expected if the child was typically developing or had better communication skills. The $37 \%$ who disagreed or had no opinion on if their relationship would be different were not necessarily siblings of independent communicators. As a follow-up question was not asked, it is not possible to know why they felt that way. During the course of the visit, several typical siblings mentioned that they did not feel the need to think about their sibling as being without a disability because that is all they knew and could not imagine things being any other way. One could speculate that this may be a reason for not thinking that the relationship could be different if their sibling had different communication skills.

Ninety-seven percent of the typical siblings also reported that they understood what their sibling was saying most of the time or all of the time. Considering that many of these children had significant difficulties with communication this is somewhat surprising. Stoneman, et al. (1987) found that in naturalistic interactions, typical siblings were able to bridge the gap in competencies with their sibling with a disability and play together in activities that worked for them. Although this finding pertains to play and not to communication, it could be that children with disabilities and their typical siblings find ways to communicate and understand each other in a similar way. 
Ninety-three percent of the typical siblings saw their primary role in their sibling's life as helper, babysitter, playmate, or both helper and playmate. The typical siblings indicated that they helped their sibling primarily with speech/communication and day-to-day skills. They helped with reading/homework, sports, behavior, and socializing to a lesser degree. This is consistent with literature demonstrating the asymmetrical nature of the sibling relationship for sibling dyads including a child with a disability. Typically developing siblings often engage in helping and teaching behaviors such as babysitting and day-to-day physical care activities of feeding, dressing, etc (Abramovitch et al., 1987; Hannah \& Midlarsky, 2005; McHale \& Gamble, 1989; Stoneman et al., 1991).

Finally, when asked to talk generally about their sibling with a disability, the typical siblings responded in a variety of ways but mostly talked about their personality characteristics, followed by problems related to having a sibling with a disability, communication skills, things they liked to do and lastly, responses specific to their disability. It is interesting to note that although $20 \%$ of the siblings mentioned problems related to having a sibling with a disability, the majority of the typical siblings first response when asked to tell the primary investigator about their sibling had nothing to do with the disability in and of itself. This may indicate a level of acceptance that siblings have for their brother or sister with a disability and a tendency to look beyond the disability itself and see other qualities and characteristics when describing their sibling.

The descriptive results from this questionnaire allowed for an examination of how the typically developing siblings felt about the communication skills of their siblings with a disability, the kinds of things that they do together, as well as their perceptions about the role that their siblings' communication plays in their relationship. While they are consistent with what we 
know about sibling relationships for children with disabilities, it also provides some insight to the unique role of communication. Although, typical siblings acknowledged the fact that their relationship would be different if their sibling with a disability had different communication skills, it did not lessen the importance of that sibling in their life. Most striking, it did not affect how well they were able to communicate with their siblings. Not one of the typical siblings indicated that they did not communicate with their sibling with a disability. All siblings indicated that they found ways to communicate and interact with their siblings in a way that was meaningful for them.

\section{Limitations}

There are several limitations to this study that should be mentioned. The primary limitation concerns the sample size. Data were collected for 30 sibling dyads, half of the original goal of 60. Although the analyses such as those examining warmth/closeness and conflict likely would have remained non-significant no matter what the sample size, the ANOVA analysis pertaining to rivalry, and the regressions for rivalry and relative status that were approaching significance, were underpowered. It is probable that these analyses would have been significant had the proposed sample size of 60 been attained. Therefore it will be important in future studies to ask these same questions with a larger sample of sibling dyads.

A second limitation to this study was the composition of the sample. Eighty-percent of the sample was Caucasian and consisted mostly of middle class families who all had at least a high school education with the majority having college degrees and beyond. Participation depended on parents receiving information about the study and contacting the primary investigator. Most of the parents who contacted the study were highly involved in various disability organizations and family support networks. Therefore this sample was likely a specific 
subset of families and siblings of children with disabilities and may not represent siblings from the majority of the disability population.

A third limitation to this study was the use of parent report to create the communication status groups. In the literature, the use of parent report has shown high reliability and validity on measures of early child language development for both clinical and research purposes (Dale, 1991; Fenson et al., 1994). It also differentiated groups appropriately in this particular sample. However, it will be important for future studies to recruit children based on specific communication and language characteristics, rather than parent report in order to replicate these findings.

\section{Implications and future directions}

This study confirms and extends the large body of literature examining sibling relationships in families of children with disabilities. This is the first study to date that has grouped children with disabilities based on their communication skill and that has specifically examined communication interaction patterns for siblings of children with disabilities. While there is a larger body of literature examining parent-child communication interaction patterns, there are not any that look specifically at siblings of children with intellectual disabilities. It appears that while typically developing siblings adjust the complexity of their speech depending on the communication skills of their sibling with a disability, they also dominate the interaction using longer turns which does not allow for the sibling with a disability to be an equal partner in the interaction. Future research should continue to investigate these communication interaction variables to gain a more complete understanding of sibling interaction patterns.

There were several findings that support previous literature while some findings are not consistent with what the literature to date would suggest. Consistent with previous literature, 
findings from this study indicate that sibling relationships for children with disabilities are generally positive and low in conflict. While overall, this study confirms the asymmetrical nature of the sibling relationship; current findings were not in the direction that was expected based on the literature. In this study, it was the siblings of independent communicators who exhibited the highest levels of asymmetry in the relationship. It will be important for future studies to specifically group children by communication ability in order to determine if this finding is representative of children with disabilities. The observational data from this study confirm the notion put forth by Kaminsky and Dewey (2001) that typical siblings often report more positive sibling relationships than what are observed in actual interactions. It will be important for future research to employ both observational and self-report data on a larger sample to generalize these findings. Finally, the information gained from the communication questionnaire gives us insight into how typical siblings perceive the communication skills of their sibling with a disability. About one-third of the siblings reported that their brother or sister with a disability needed help with communication and speech skills yet all were able to successfully communicate with each other.

\section{Conclusions}

In conclusion, this study represents an important first step in understanding the unique role of communication skills in the sibling relationship for families of children with disabilities. It established that when children with disabilities are grouped together according to their communication abilities, dimensions of sibling relationship quality are different than what is expected based on the overall literature for children with disabilities. The literature has established that having a sibling with a disability is a complex experience that brings with it both rewards and challenges. In this sense, communication and language skills are important 
variables to add to the literature to further elucidate the experience of sibling relationships in families of children with disabilities.

\section{References}

Abramovitch, R., Stanhope, L., Pepler, D., \& Corter, C. (1987). The influence of Downs syndrome on sibling interaction. Journal of Child Psychology and Psychiatry, 28, 865879.

Anderson, E. R., Hetherington, E., Reiss, D., \& Howe, G. (1994). Parents' nonshared treatment of siblings and the development of social competence during adolescence. Journal of Family Psychology, 8, 303-320.

Bakeman, R., \& Gottman, J. M. (1997). Observing interaction: An introduction to sequential analysis (2nd ed.). Cambridge: Cambridge University Press.

Bank, S., \& Kahn, M. D. (1997). The sibling bond. New York: Basic Books.

Barr, J., Mcleod, S., \& Daniel, G. (2008). Siblings of children with speech impairment: Cavalry on the hill. Language, Speech, and Hearing Services in Schools, 39, 21-32.

Begun, A. L. (1989). Sibling relationships involving developmentally disabled people. American Journal on Mental Retardation, 93, 566-574.

Blackstone, S. W., \& Hunt-Berg, M. (2003). Social networks: A communication inventory for idividuals with complex commmunication needs and their communication partners. Monterey, CA: Augmentative Communication, Inc.

Brody, G. H. (1998). Sibling relationship quality: Its causes and consequences. Annual Review of Psychology, 49, 1-24.

Brody, G. H., Stoneman, Z., Davis, C. H., \& Crapps, J. M. (1991). Observations of the role relations and behavior between older children with mental retardation and their younger 
siblings. American Journal on Mental Retardation, 95, 527-536.

Brody, G. H., Stoneman, Z., \& MacKinnon, C. E. (1996). Contributions of maternal childrearing practices and play contexts to sibling interactions. Journal of Applied Developmental Psychology, 7, 225-236.

Brody, G. H., Stoneman, Z., \& McCoy, J. K. (1994). Forecasting sibling relationships in early adolescence from child temperaments and family processes in middle childhood. Child Development, 65, 771-784.

Bronfenbrenner, U. (1977). Toward an experimental ecology of human development. American Psychologist, 32, 513-531.

Bronfenbrenner, U. (1986). Ecology of the family as a context for human development: Research perspectives. Developmental Psychology, 22, 723-742.

Buhrmester, D. (1992). The developmental courses of sibling and peer relationships. In F. Boer \& J. Dunn (Eds.), Children's sibling relationships: Developmental and clinical issues. Hillsdale, NJ, England: Lawrence Erlbaum Associates, Inc.

Buhrmester, D., \& Furman, W. (1990). Perceptions of sibling relationships during middle childhood and adolescence. Child Development, 61, 1387-1398.

Cicirelli, V. G. (1995). Sibling relationships across the life span. New York: Springer.

Cuskelly, M. (1999). Adjustment of siblings of children with a disability: Methodological issues. International journal for the advancement of counselling, 21, 111-124.

Cuskelly, M., \& Gunn, P. (2003). Sibling relationships of children with Down syndrome: Perspectives of mothers, fathers, and siblings. American Journal on Mental Retardation, $108,234-244$.

Dale, P. S. (1991). The validity of a parent report measure of vocabulary and syntax at 24 
months. Journal of Speech and Hearing Research, 34(565-571).

Dallas, E., Stevenson, J., \& McGurk, H. (1993). Cerebral-palsied children's interactions with siblings: Influence of severity of disability, age, and birth order. Journal of Child Psychology and Psychiatry, 34, 621-647.

Dowden, P. A. (1999). Augmentative and alternative communication for children with motor speech disorders. In A. Caruso \& E. A. Strand (Eds.), Clinical management of motor speech disorders of children (pp. 345-384). New York: Thieme Publishing Co.

Dowden, P. A., \& Cook, A. M. (2002). Selection techniques for individuals with motor impairments. In J. Reichle, D. Beukelman \& J. Light (Eds.), Implementing an augmentative communication system: Exemplary strategies for beginning communicators (pp. 395-432). Baltimore, MD: Paul H. Brookes Publishing Co.

Dunn, J. (1992). Sisters and brothers: Current issues in developmental research. In J. Dunn \& F. Boer (Eds.), Children's sibling relationships: Developmental and clinical issues (pp. 118). Hillsdale, NJ: Erlbaum.

Dunn, J. (1996). Brothers and sisters in middle childhood and adolescence: Continuity and change in individual differences. In G. H. Brody (Ed.), Sibling relationships: Their causes and consequences (pp. 31-46). Stamford, CT: Ablex.

Dunn, J., Slomkowski, C., \& Beardsall, L. (1994). Sibling relationships from the preschool period through middle childhood and adolescence. Developmental Psychology, 3, 315324.

Dunn, L. M., \& Dunn, D. M. (2007). Peabody Picture Vocabulary Test. San Antonio, TX: Pearson.

Dykens, E. M. (2005). Happiness, well-being, and character strengths: Outcomes for families 
and siblings of persons with mental retardation. Mental Retardation, 43, 360-364.

Eisenberg, L., Baker, B. L., \& Blacher, J. (1998). Siblings of children with mental retardation living at home or in residential placement. Journal of Child Psychology and Psychiatry, 39, 355-363.

Farber, B. (1960). Effects of a severely mentally retarded child on family integration. Monographs of the Society for Research on Child in Child Development, 24, 1-112.

Fenson, L., Dale, P. S., Reznick, J. S., Bates, E., Thal, D. J., \& Pethick, S. J. (1994). Variability in early communication development. Monographs of the Society for Research in Child Development, 59 (5, Serial No. 242).

Fleiss, J. L. (1981). Statistical methods for rates and proportions. New York: Wiley.

Floyd, F. J., Purcell, S. E., Richardson, S. S., \& Kupersmidt, J. B. (2009). Sibling relationship quality and social functioning of children and adolescents with intellectual disability. American Journal on Intellectual and Developmental Disabilities, 114, 110-127.

Furman, W., \& Buhrmester, D. (1985). Children's perceptions of the qualities of sibling relationships. Child Development, 56, 448-461.

Gallagher, P. A., Powell, T. H., \& Rhodes, C. A. (2006). Brothers and sisters: A special part of exceptional families (3rd ed.). Baltimore, MD: Paul H. Brookes Publishing.

Hannah, M. E., \& Midlarsky, E. (2005). Helping by siblings of children with mental retardation. American Journal on Mental Retardation, 110, 87-99.

Hastings, R. P., \& Taunt, H. M. (2002). Positive perceptions in families of children with developmental disabilities. American Journal onMental Retardation, 107, 116-127.

Kaminsky, L., \& Dewey, D. (2001). Sibling relationships of children with Autism. Journal of Autism and Developmental Disorders, 31, 399-410. 
Kenny, D. A., Kashy, D. A., \& Cook, W. L. (2006). Dyadic Data Analysis. New York, NY: Guilford Press.

Knott, F., Lewis, C., \& Williams, T. (1995). Sibling interactions of children with learning disabilities: A comparison of autism and Down's syndrome. Journal of Child Psychology and Psychiatry, 6, 965-976.

Kowal, A., \& Kramer, L. (1997). Children's understanding of parental differential treatment. Child Development, 68, 113-126.

McGillicuddy-DeLisi, A. V. (1993). Sibling interactions and children's communicative competency. Journal of Applied Developmental Psychology, 14, 365-383.

McHale, S. M., \& Gamble, W. C. (1989). Sibling relationships of children with disabled and nondisabled brothers and sisters. Developmental Psychology, 25, 421-429.

McHale, S. M., Sloan, J., \& Simeonsson, R. J. (1986). Sibling relationships or children with autistic, mentally retarded, and nonhandicapped brothers and sisters Journal of Autism and Developmental Disorders, 16, 399-413.

Miller, J., \& Chapman, R. (1985). Systematic analysis of language transcripts. Madison, WI: University of Wisconsin.

Minuchin, P. P. (1988). Relationships within the family: A systems perspective on development. In R. A. Hinde \& J. Stevenson-Hinde (Eds.), Relationships within families: Mutual Influences. New York: Oxford University Press.

Neece, C. L., Blacher, J., \& Baker, B. L. (2010). Impact on siblings of children with intellectual disability: The role of child behavior problems. American Journal on Intellectual and Developmental Disabilities, 115, 291-306.

Pellegrini, A. D., Brody, G. H., \& Sigel, I. E. (1985). Parents' teaching strategies with their 
children: The effects of parental and child status variables. Journal of Psycholinguistic Research, 14, 509-521.

Pilowsky, T., Yirmiya, N., Doppelt, O., Gross-Tsur, V., \& Shalev, R. (2004). Social and emotional adjustment of siblings of children with autism. Journal of Child Psychology and Psychiatry, 45, 855-865.

Roeyers, H., \& Mycke, K. (1995). Siblings of children with autism, with mental retardation, and with normal development. Child: Care, Health, and Development, 21, 305-319.

Romski, M. A., \& Sevcik, R. A. (1996). Breaking the speech barrier. Baltimore, MD: Brookes.

Romski, M. A., Sevcik, R. A., Adamson, L. B., \& Bakeman, R. A. (2005). Communication patterns of individuals with moderate or severe cognitive disabilities: Interactions with unfamiliar partners. American Journal on Mental Retardation, 110, 226-238.

Rossiter, L., \& Sharpe, D. (2001). The siblings of individuals with mental retardation: A quantitative integration of the literature Journal of Child and Family Studies, 10, 65-84.

Smith, A. L. (2010). Sibling Communication Questionnaire.

Sparrow, S. S., Cicchetti, D. V., \& Balla, D. A. (2005). Vineland adaptive behavior scales (2nd ed.). Circle Pines, MN: AGS Publishing.

Stocker, C., Dunn, J., \& Plomin, R. (1989). Sibling relationships: Links with child temperament, maternal behavior, and family structure. Child Development, 60, 715-727.

Stoneman, Z. (1993). Common themes and divergent paths. In Z. Stoneman \& P. W. Berman (Eds.), The effects of mental retardation, disability, and illness on sibling relationships (pp. 355-365). Baltimore: Brookes.

Stoneman, Z. (1998). Research on siblings of children with mental retardation: Contributions of developmental theory and etiology. In J. A. Burack, R. M. Hodapp \& E. Zigler (Eds.), 
Handbook of Mental Retardation and Development. (pp. 669-692). Cambridge, UK: Cambridge University Press.

Stoneman, Z. (2001). Supporting positive sibling relationships during childhood. Mental Retardation and Developmental Disabilities Research Reviews, 7, 134-142.

Stoneman, Z. (2005). Siblings of children with disabilities: Research Themes. Mental Retardation 43, 339-350.

Stoneman, Z., \& Brody, G. H. (1984). Research with families of severely handicapped children: Theoretical and methodological considerations. In J. Blacher (Ed.), Severely handicapped young children and their families: Research in review (pp. 179-214). New York: Academic Press.

Stoneman, Z., \& Brody, G. H. (1993). Sibling relations in the family context. In Z. Stoneman \& P. W. Berman (Eds.), The effects of mental retardation, disability, and illness on sibling relationships: Research issues and challenges. (pp. 3-30). Baltimore, MD, England: Paul H. Brookes Publishing.

Stoneman, Z., Brody, G. H., Davis, C. H., \& Crapps, J. M. (1987). Mentally retarded children and their same-sex siblings: Naturalistic in-home observations. American Journal on Mental Retardation, 92, 290-298.

Stoneman, Z., Brody, G. H., Davis, C. H., \& Crapps, J. M. (1989). Role relations between children who are mentally retarded and their older siblings: Observations in three inhome contexts. Research in Developmental Disabilities, 10, 61-76.

Stoneman, Z., Brody, G. H., Davis, C. H., Crapps, J. M., \& Malone, D. M. (1991). Ascribed role relations between children with mental retardation and their younger siblings. American Journal on Mental Retardation, 95, 537-550. 
Tabachnick, B. G., \& Fidell, L. S. (2007). Using multivariate statistics. Boston, MA: Pearson Education Inc.

Vandell, D. L., Minnett, A. M., \& Santrock, J. W. (1987). Age differences in sibling relationships during middle childhood. Journal of Applied Developmental Psychology, 8, 247-257.

Williams, K. T. (2007). Expressive Vocabulary Test (2nd ed.). San Antonio, TX: Pearson Publishing. 


\section{Appendix}

\section{Communication Questionnaire}

1. Tell me a little about your sibling. What do I need to know about (Name)?

2. What kinds of activities do you like to do with your sibling?
a. Play outdoors
b. Play games
c. Play with toys
d. Play sports
e. Read books
f. Watch TV
g. Other

3. What kinds of things does (Name) need help with?

4. Tell me how you feel about this statement: (Name) is a very important person in my life. Strongly agree Agree No opinion Disagree Strongly Disagree

5. How would you describe your sibling's communication skills?
a. Everyone understands what he/she is trying to say
b. My family and other caregivers understand what my sibling is saying
c. Tries to communicate but people outside the family don't understand him/her
d. He/she does not talk very much

6. In what ways do you and your sibling communicate with each other? You can choose multiple ways.
a. Speech
b. Gestures/Manual sign 
c. Speech generating device

d. Do not communicate with each other

e. Other

7. How well do you understand what your sibling is saying?

All the time most of the time sometimes rarely never

8. Tell me how you feel about this statement: My relationship with (Name) would be different if he/she had different communication skills.

Strongly agree Agree No opinion Disagree Strongly Disagree

9. What do you see as your primary role in your sibling's day to day life?
a. Helper
b. Babysitter
c. Playmate
d. Other

10. Is there anything else you want to tell me about you and (Name)? 